\title{
Does hosting a professional sports team benefit the local community? Evidence from property assessments
}

\author{
John Charles Bradbury ${ }^{1}$ (i)
}

Received: 7 June 2021 / Accepted: 10 January 2022 / Published online: 3 February 2022

(c) The Author(s), under exclusive licence to Springer-Verlag GmbH Germany, part of Springer Nature 2022

\begin{abstract}
Local governments often justify subsidizing sports stadiums as economic development projects that have positive returns on investment. If this is true, economic and quality-of-life spillovers that are capitalized in local property values ought to generate additional tax revenue for host municipalities through increased property assessments. This analysis uses the synthetic control method to estimate the effect of a new publicly-funded professional baseball stadium and team relocation on property assessments in Cobb County, Georgia. Cobb assessment values did not increase relative to other metro-Atlanta counties following the stadiums' announcement or opening, which is inconsistent with the stadium having a positive fiscal impact, even with its desirable location and accompanying mixed-used development. The findings are consistent with past economic studies and are likely generalizable to other stadium projects.
\end{abstract}

Keywords Sports stadiums · Local economic development $\cdot$ Social benefits . Property values $\cdot$ Property taxes $\cdot$ Synthetic control method

JEL Classification $\mathrm{H} 41 \cdot \mathrm{H} 71 \cdot \mathrm{L} 83 \cdot \mathrm{R} 58 \cdot \mathrm{Z} 23 \cdot \mathrm{Z} 28$

\begin{abstract}
Disclosures: The author is a faculty affiliate of the Bagwell Center for the Study of Markets and Economic Opportunity at Kennesaw State University. The author serves as an appointed member on the Development Authority of Cobb County, which often participates in development projects in Cobb County, including projects that involve ANLBC. This project is unrelated to his role on this County government committee (which is uncompensated), and he has no financial interest in any related project. The author is solely responsible for the content in this article. No party had the right to review the paper prior to its circulation.
\end{abstract}

John Charles Bradbury

jcbradbury@kennesaw.edu

1 Department of Economics, Finance, and Quantitative Analysis, Michael J. Coles College of Business, Kennesaw State University, 560 Parliament Garden Way NW, 30144 Kennesaw, Georgia 
Property values in Ott's District 2, which includes Cumberland and east Cobb, have increased by almost \$11 billion since 2013, according to the data the commissioner shared last month. Ott says Cumberland alone has seen significant developments step up to the plate in the wake of the Braves' announcement of their entry into Cobb... "As those come online, you start to increase property taxes, and it's people in the area. They weren't being proposed before (the Braves arrival).” (Gargis 2017)

\section{Introduction}

It has become common for local governments to subsidize the relocation and retention of professional sports teams through the construction and operation of sports venues. Since 1970 more than 120 sports stadiums and arenas have opened in North America to host major-league franchises, with public subsidies covering a majority of total construction costs (Humphreys 2019). This does not include funding of minor-league and college sports facilities that also often benefit from public subsidies. The penchant for funding sports venues among local governments in the United States and Canada remains strong, and thus the economic justifications for these projects is an important subject for public policy.

Stadium and arena subsidies are often defended as economic development projects, based on the expectation that associated commercial activity will spill over onto the surrounding community to stimulate economic growth. However, consensus findings reported in the large literature on the economic impacts of sports facilities and events offer little support for the hypothesis that sports-related commerce stimulates the local economy (Coates and Humphreys 2008). Spending on sports appears to emanate from intrajurisdictional transfers among residents who sacrifice other local consumption options rather than generating net new economic activity in the community. Thus, the continued subsidization of sports venues appears to be unjustified, which represents a curious example of a persistent government failure.

Despite the lack of observable impacts on tangible measures of economic performance (e.g., income, output, employment, etc.), the presence of a professional sports franchise may confer social benefits to the community through neighborhood externalities and non-excludable public good amenities that enhance residents' quality of life. These potential unpriced benefits are not captured in sports consumption but are still valued by local residents. Rosentraub (2014) argues that amenity spillovers from hosting a professional sports team make the region more attractive and livable for businesses and residents, which ultimately results in positive returns on public investments in sports stadiums: "As investments, the tax dollars expended for venues have generated positive net financial returns. Cities can and do win in the sense that the financial returns the public sector receives are more than the funds expended"(p. $\mathrm{xv}$ ). If professional sports teams generate positive fiscal impacts through existence spillovers, then public subsidization of sports venues and their widespread political support may be justified. 
In a Tiebout (1956) and Oates (1969) framework, the welfare gains from spillovers that derive from hosting a professional sports team should be reflected in local property values. As Carlino and Coulson (2004) notes, "If people like having a professional sports franchise in their community, they are presumably willing to pay for it, if not directly through the purchase of season tickets, then indirectly through an increased willingness to pay for housing in the area" (p. 27). Increased local property values should translate into greater property assessments that raise additional property tax revenue for the host municipality, providing another channel through which a stadium may have a positive fiscal impact on its community. Therefore, fiscal effects from stadium spillovers on resident taxpayers ought to be observable in property assessments. Though economists have examined neighborhood effects of stadiums on local real estate prices, the extended fiscal impact through property assessments has received little study.

In 2013, Atlanta National League Baseball Club (ANLBC) of Major League Baseball (MLB) announced that it was moving its team ("Atlanta Braves") from its downtown Atlanta stadium (Turner Field) in Fulton County to the suburban business district of Cumberland in adjacent Cobb County. As part of the agreement to host the team, Cobb County committed $\$ 300$ million in public funds to subsidize the construction and operation of a new stadium (Truist Park). ${ }^{1}$ A novel feature of the stadium is that it is part of a broader mixed-use development, which is owned and operated by ANLBC. The stadium is also uniquely positioned within metropolitan Atlanta to attract new customers and residents from the region, due to its location at the junction of major highways on the Cobb County border. Thus, the stadium is placed ideally to facilitate economic activity by attracting cross-border consumption and migration from non-Cobb residents and expand the County's taxbase through added sales and property tax collections.

Cobb Board of Commissioners Chairman Tim Lee touted the stadium development as an economic "home run for Cobb County," which would stimulate economic growth and pay for itself through increased tax revenue derived from the project, declaring that the stadium would be "the single greatest economic development project in the modern history of Cobb County" (Klepal 2013; Lee 2016). However, the predicted impacts have not manifested in the local economy. Studies of the business district surrounding the stadium (Bradbury 2022) and County sales tax receipts (Bradbury 2021) do not identify significant increases in economic activity following the opening of the ballpark.

This analysis extends the examination of the stadium's impact further by observing changes in county-wide property assessments. Added residential and commercial amenities from the stadium should be evident in local property values, which ought to reflect the social and economic value of the stadium borne by the citizens who funded the project. Increased property values should correspondingly grow the County's tax digest to help cover the costs of the stadium. Though the stadium may not have directly stimulated sufficient commercial activity to justify the public subsidies, the total social benefits may rise to that level.

\footnotetext{
1 The stadium was named SunTrust Park during its first three years of operation, but changed its name along with its naming rights sponsor in 2020. For simplicity, I refer to the stadium as Truist Park in this article.
} 
I use the synthetic control method to compare Cobb's property assessments before and after the announcement and opening of Truist Park relative to other metroAtlanta counties, which provide a donor pool of control units to generate a reasonable counterfactual estimate of Cobb County property assessment values absent the stadium. Synthetic control comparisons indicate that Cobb property assessments did not deviate from their pre-stadium trajectories following the announcement or opening of the stadium. Instead, Cobb's property tax digest growth has been typical among metro-Atlanta counties, which indicates that post-stadium growth in Cobb property assessments reflects a regional trend rather than a response to the stadium development. The estimates are robust to sensitivity and placebo tests. Because the team relocated within the same metropolitan area, cross-county congruence cannot reflect spillovers from the Cobb stadium onto the larger region. Though Cobb residents have borne the financial obligation of funding the stadium, they have not experienced a corresponding financial return through increased property assessments.

The findings also contribute to the regional science and economics literatures on intangible stadium spillovers, in which studies have produced mixed findings. Georgia's property assessments are regularly curated to reflect market transactions and thus capture social benefits capitalized in property values. The lack of deviation from pre-stadium trends in Cobb assessment values does not support the hypothesis that sports stadiums are strong sources of non-pecuniary social benefits to local residents.

Though this analysis is a case study, its findings are likely generalizable to other stadium projects. From its inception, Truist Park was well-suited to be successful and generate net new economic activity and tax revenue through interjurisdictional competition in the region. Its impotence despite its unique advantages indicates that most stadium projects are unlikely to have strong positive effects on local communities that would justify standard levels of public subsidies typically provided for stadium projects.

\section{Background}

On November 11, 2013, ANLBC, which is a subsidiary of Liberty Media Corporation, announced that it was moving its MLB team operations from Turner Field in downtown Atlanta to the suburban business district of Cumberland in Cobb County. ${ }^{2}$ The relocation was unexpected when announced, because the team was playing in a relatively new stadium with modern ballpark amenities, and the club was not openly advertising its intentions to relocate. Similarly, Cobb County was not seeking to attract an MLB team, as county residents were largely fans of the existing metro-Atlanta franchise and lacked the population (approximately 720,000

\footnotetext{
${ }^{2}$ Cumberland Community Improvement District (CID) is a self-taxing business improvement district organized for the purpose of facilitating commerce among local businesses, which is located on the south-eastern border in unincorporated Cobb County. Truist Park lies near the center of the district, which covers approximately seven square miles.
} 
residents) to support a separate club. On November 26, the Cobb Board of Commissioners approved a memorandum of understanding that committed the County to devote $\$ 300$ million to assist with construction of a new ballpark to host the club.

The County planned to fund its portion of the $\$ 672$ million stadium through several mechanisms; however, a majority of funds are collected from the entire county. The largest contribution is from the County's general fund through county-wide property tax collections, much of it derived from the reallocation of revenue from park bonds that were scheduled to be retired. ${ }^{3}$

Though most studies of the impacts of the presence of sports teams and venues do not identify strong economic impacts, Truist Park is a unique stadium project with attributes lacking in other stadium developments, which may generate greater economic and social benefits for the community. Stadium advocates highlighted the novelty of the project in response to objections from critics who pointed to the failures of past stadium projects to recoup their investments.

First, the stadium is part of The Battery Atlanta ("the Battery") mixed-use development, which is owned and operated by ANLBC. In addition to the stadium, ANLBC invested another \$400 million in purchasing and developing land around the stadium to be part of an entertainment, retail, office, and residential campus. In total, the $\$ 1.1$ billion stadium development was designed to attract commerce as a year-round economic hub that generates revenue even when the team is not playing, expanding its development footprint in a halo that extends to other Cobb businesses and residents. Club President and CEO Mike Plant emphasized this aspect when touting the stadium development's impact on the Cobb:

Our collective public-private partnership always was focused on the mixeduse development. This was never about building a professional ballpark as a standalone facility. I know I've said over a hundred times on behalf of our organization those don't pencil out most of the time. This has been about \$1.1 billion in private investment into the Battery (Deere 2021).

Second, the stadium's location facilitates easy access for the existing local fanbase that includes non-Cobb residents who are shifting their baseball consumption from Fulton County to the adjacent tax jurisdiction of Cobb County. Truist Park is situated near the edge of Cobb, on its border with the City of Atlanta and at the junction of two major interstates that can be accessed by fans throughout the metro area. Thus, the stadium development is well placed to increase net economic activity within Cobb that was previously not present, which may result in greater tax revenue to the County through added sales and property taxes. Associated new residential construction at the Battery and the juxtaposition of the area to the City of Atlanta and its transportation arteries might also facilitate in-migration from metro-Atlanta residents who value proximity to the ballpark.

\footnotetext{
${ }^{3}$ Other revenue sources include a reallocation funding from its existing county-wide hotel tax, a new county-wide car rental tax, and two new special tax districts near the stadium that assess additional taxes on local businesses, multifamily housing units, and hotels (Gillooly 2013b).
} 
The stadium also provides an opportunity for Cobb County to distinguish itself among the Atlanta community and foster civic pride among residents. Hosting an MLB club demonstrates that Cobb is desirable place to live and work, and businesses may be attracted by the team's presence; thus, migrating businesses may choose relocation to Cobb over downtown Atlanta or other local jurisdictions. Furthermore, county residents may value the option of local access to the ballpark and other amenities. At government meetings and town halls following the project announcement, stadium advocates wore shirts with the logo "Cobb: Home of the Braves" to promote the positive impact that hosting an MLB team would have for Cobb's reputation (Gillooly 2013a).

Thus, the unexpected relocation of ANLBC to Cobb County provides a natural experiment to identify the effect of a professional sports franchise on its host community. Its mixed-use development design and placement within a metropolitan area ought to enhance its effects on the host juridiction that should be evident in local property assessments.

\section{Empirical analysis}

\subsection{Motivation}

The primary motivation for this analysis is to identify the potential fiscal impact of a new stadium and hosting a professional sports team on a host municipality through property tax collections. As is common with most stadium projects, Truist Park advocates predicted significant financial returns flowing to the County treasury that would more than cover the public costs. Commissioner Lee described the subsidy as a sound financial endeavor: "As an economic development project this small investment by the residents will bring back and yield a significant growth in our digest, in our sales tax, in our economic viability, it is a relatively small investment for a huge return not only for the Cumberland area but all of Cobb County" (Gillooly 2013b). Like most local governments, the primary revenue source of Cobb's general fund is property taxes; thus, fiscal returns should manifest through increased property assessments resulting from the stadium's presence.

The findings also contribute to the economics literature on the non-pecuniary benefits of sports teams and stadiums. While most studies do not find large tangible economic impacts from sports facilities and events, there is some evidence that the presence of teams may have positive social benefits on host communities. Even if economic benefits are not evident, hosting a professional franchise may generate welfare-improving spillovers for residents that justify subsidies to rectify a market failure (Matheson 2019). Several studies have examined the social non-use benefits of hosting professional sports teams using two empirical strategies.

The first approach uses contingent valuation method (CVM) surveys of local communities to identify residents' willingness to pay for hosting a professional sports team to quantify its option value. Though CVM estimates identify positive existence values from local franchises, the gains generally are well below the subsidies paid to teams (Johnson, Groothuis and Whitehead 2001; Johnson, Mondello 
and Whitehead 2007; Fenn and Crooker 2009; Johnson, Whitehead, Mason and Walker 2012).

This analysis uses the second method of observing property values in the surrounding community to estimate stadium spillovers that are capitalized into real estate prices. The theory that property values capture the social costs and benefits of collective consumption goods to residents originates from Tiebout (1956) and Oates (1969), which posit that land prices reflect resident benefits and tax costs of the provision of publicly-provided local services. Public good and externality spillovers from hosting professional sports teams ought to be similarly capitalized into property values. This approach has produced mixed findings, which I discuss below. Georgia property assessments are governed by objective procedures designed to reflect the fair market value of property; thus, the assessments are a reasonable proxy of market values. 4

In its examination of the impact of National Football League (NFL) teams on social benefits to metropolitan areas, Carlino and Coulson (2004) begins with the basic hypothesis that if professional sports teams contribute quality-of-life amenities, then hosting a team should be reflected in increased local residential rental prices. The authors use a hedonic pricing model that accounts for housing and city characteristics to observe monthly residential rents in large US metropolitan areas, in order to estimate the impact of hosting an NFL team. The authors find higher rents in cites with NFL teams, which they infer reflects the added value that residents place on living in an NFL-hosting city. Though Coates, Humphreys and Zimbalist (2006) contends that the findings are not robust, and the original authors defend their estimates (Carlino and Coulson 2006), the idea that property values reflect total social benefits of hosting professional sports teams remains important for motivating the design of this study. Tu (2005) similarly uses housing prices to examine the impact of a new NFL stadium on its neighborhood. The study employs a difference-in-differences strategy to estimate changes in residential property values in the neighborhood surrounding a new stadium following the move of Washington, DC's professional football team from its inner-city location to a Maryland suburba move that is similar to ANLBC's move from downtown Atlanta to Cobb County. The estimates indicate a positive impact on nearby home prices, which may reflect amenity spillovers from hosting the team. Positive stadium impacts on property also have been identified from US major-league professional sports stadiums (Feng and Humphreys 2012), professional soccer stadiums in England (Ahlfeldt and Kavetsos

\footnotetext{
${ }^{4}$ In Georgia, all real property is assessed at 40 percent of its fair market value for tax collection purposes. Counties are required to assess property annually and compare assessments to recent sales to ensure that they reflect up-to-date market transactions. The state mandates that each county's Board of Tax Assessors must provide regular estimates of all property in its jurisdiction to the State Revenue Commissioner who reviews the assessments to assure uniformity within and across counties (Georgia Department of Revenue 2017, 2021a, c, d). Accuracy and uniformity were particularly important to the state for most of the sample, because Georgia collected a state-wide property tax through 2015. Georgia assessed a 0.25 millage rate through 2011. In 2012, the state began a gradual phase out of the state-level property tax by 0.05 mills per year, until the tax was no longer collected in 2016 .
} 
2014) and the US (Feng and Humphreys 2018), and commercial property near a National Basketball Association (NBA) arena (Propheter 2019).

While much of the policy discussion regarding the impact of sports on the local community focuses on positive spillovers, sports events are associated negative externalities, which may be a detriment to nearby businesses and residents and thus may lower property values. Disamenities include crime (Mares and Blackburn 2019; Marie 2016; Montolio and Planells-Struse 2019; Pyun 2019; Rees and Schnepel 2009; Yu, Mckinney, Caudill and Mixon Jr. 2016), traffic congestion (Humphreys and Pyun 2018), and pollution (Locke 2019). Dehring, Depken and Ward (2007) identifies mostly negative announcement effects from an NFL franchise relocation, which were consistent with expected increased tax obligations. Humphreys and Nowak (2017) finds negative effects evident in NBA team departures.

Whether the net impact of sports-related spillovers is positive or negative is an empirical question that should be reflected in local property values. This analysis adds to the literature on the economic and social benefits of hosting a professional sports team by estimating Truist Park's impact on Cobb County property assessments. The findings regarding Cobb's stadium development have implications for other local municipalities, which regularly commit public funds to subsidize stadiums.

\subsection{Cross-county comparison}

A simple time-series comparison of Cobb's assessment values before and after the stadium is not sufficient to identify the impact of the stadium development, because Cobb experienced growing property values during this period that was unrelated to ANLBC's relocation, like much of the Atlanta area. Metro-Atlanta counties provide a useful control group of counties experiencing similar economic circumstances to estimate how Cobb's property assessments progressed relative to counties that did receive a new MLB team and stadium. Cobb is one of 29 Atlanta Metropolitan Statistical Area (MSA) counties in Georgia, which are mapped in Fig. 1, along with baseball stadium locations and major interstate highways.

The Georgia Department of Revenue (2021b) reports annual property digest assessments on its website for Georgia counties. Table 1 reports the mean assessed value per acre for all metro-Atlanta counties during the study sample, from 1999 to 2019. Cobb's property is the third most valuable among the cohort, and its normalized value is most similar to three other core metro-Atlanta counties of DeKalb, Fulton, and Gwinnett, which have assessed values that are much higher than other counties. 60 percent of metro-Atlanta's population resides in these four core counties. The remaining MSA counties have strong economic and social ties to Atlanta, but they are more suburban and exurban in nature.

Treatment effects from the stadium may be evident at two points in time: at its announcement and at its opening. When a stadium project is announced, buyers and sellers receive information that should be immediately capitalized into property values if the effects can be accurately anticipated. However, the uniqueness of stadium projects and conflicting external effects on local land use may create substantial 


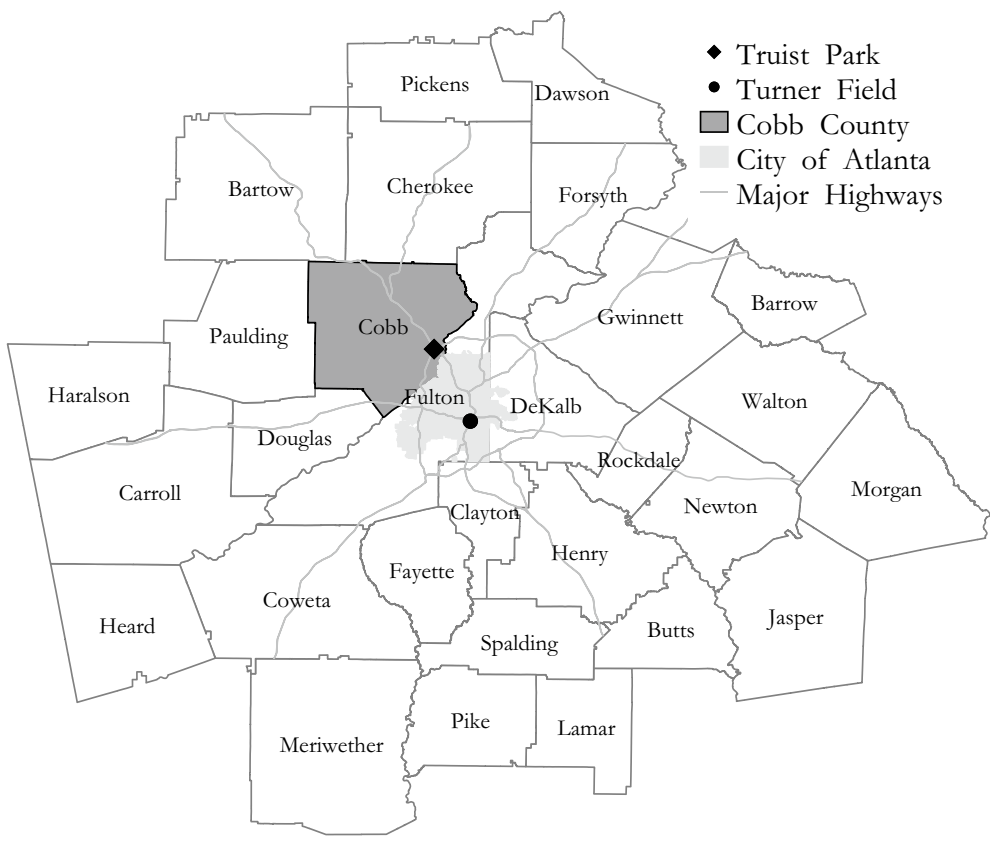

Fig. 1 Map of Metropolitan Atlanta Counties. Includes City of Atlanta boundary, major highways, and ballpark locations

Table 1 Mean value per acre by Metro-Atlanta County, 1999-2019

\begin{tabular}{llll}
\hline County & Value per acre & County & Value per acre \\
\hline Fulton & $\$ 176,977$ & Spalding & $\$ 14,634$ \\
DeKalb & $\$ 165,864$ & Walton & $\$ 14,314$ \\
Cobb & $\$ 158,914$ & Bartow & $\$ 12,304$ \\
Gwinnett & $\$ 125,177$ & Dawson & $\$ 11,141$ \\
Clayton & $\$ 99,454$ & Pickens & $\$ 10,354$ \\
Forsyth & $\$ 65,567$ & Carroll & $\$ 10,243$ \\
Fayette & $\$ 45,560$ & Butts & $\$ 6,554$ \\
Henry & $\$ 36,741$ & Morgan & $\$ 5,094$ \\
Rockdale & $\$ 36,365$ & Lamar & $\$ 4,888$ \\
Douglas & $\$ 35,671$ & Haralson & $\$ 4,818$ \\
Cherokee & $\$ 32,554$ & Pike & $\$ 4,252$ \\
Barrow & $\$ 21,007$ & Heard & $\$ 2,764$ \\
Paulding & $\$ 19,938$ & Jasper & $\$ 2,507$ \\
Coweta & $\$ 16,936$ & Meriwether & $\$ 2,397$ \\
Newton & $\$ 16,731$ & & \\
\hline
\end{tabular}

Real dollar values in 2019 dollars 
uncertainty as to how the development will unfold-e.g., enhance or deter business and residential agglomeration, produce local amenities, attract traffic and crime (Humphreys and Zhou 2015)—which may not be apparent until after the stadium opens and land use changes manifest. Previous studies of sports venues have identified announcement effects (Ahlfeldt and Kavetsos 2014; Dehring, Depken and Ward 2007) in addition to facility existence effects (Ahlfeldt and Maennig 2010; Feng and Humphreys 2018; Bradbury 2022) on nearby property values. Tu (2005) identifies both an effect from the announced move of the team, and smaller increase following the stadium's opening. Therefore, I examine the potential impacts of stadium announcement and opening treatments in this study.

As a preliminary comparison, Fig. 2 maps Cobb's change in value per acre as a percent difference relative to the year prior to the announced move to Cobb (2013) and the year prior to the stadium opening (2016). Percent differences normalize changes across counties with large differences in average property values. The figures include comparisons to all Atlanta MSA counties, and separately identifies Atlanta's central core counties of Cobb, DeKalb, Fulton, and Gwinnett. Their progressions reveal that while Cobb assessment values have increased since the stadium was announced and opened, as stadium advocates have noted, its growth has not been extraordinary among counties in the region. These simple comparisons are not indicative of a treatment effect from the stadium that ought to be reflected in changes to property assessments, as Cobb's experience has been typical.

\subsection{Synthetic control method}

While a simple comparison among counties does not suggest a stadium-induced increase in property assessments in Cobb, metro-Atlanta counties differ from Cobb in multiple ways; thus, a more-realistic counterfactual comparison is preferred. The synthetic control method provides an empirical strategy for identifying causal effects from interventions by creating a counterfactual non-intervention outcome that is more realistic than the average of untreated control units, which provides an attractive comparison for evaluating policy (Athey and Imbens 2017). It has become common tool for identifying causal effects in social science, and economists have used the synthetic control method to examine the effects of sports events on local communities, with recent studies analyzing the effects of NFL expansion on employment (Islam 2019), MLB games on crime (Pyun 2019), and hosting Olympic Games on employment (Johnson 2021).

The synthetic control method was developed in several papers by Abadie and Gardeazabal (2003) and Abadie, Diamond and Hainmueller (2010, 2015). Abadie (2021) provides a comprehensive overview of the method, which discusses relevant considerations for researchers and offers practical guidance for its application. The synthetic control approach works by exploiting the co-movement of relevant characteristics across similar units to generate the counterfactual non-intervention outcome from a weighted average of non-treated control units. Observed outcomes are then compared to the synthetic control during the post-treatment period, where divergences suggest a treatment effect. I use the synthetic control method to estimate how 


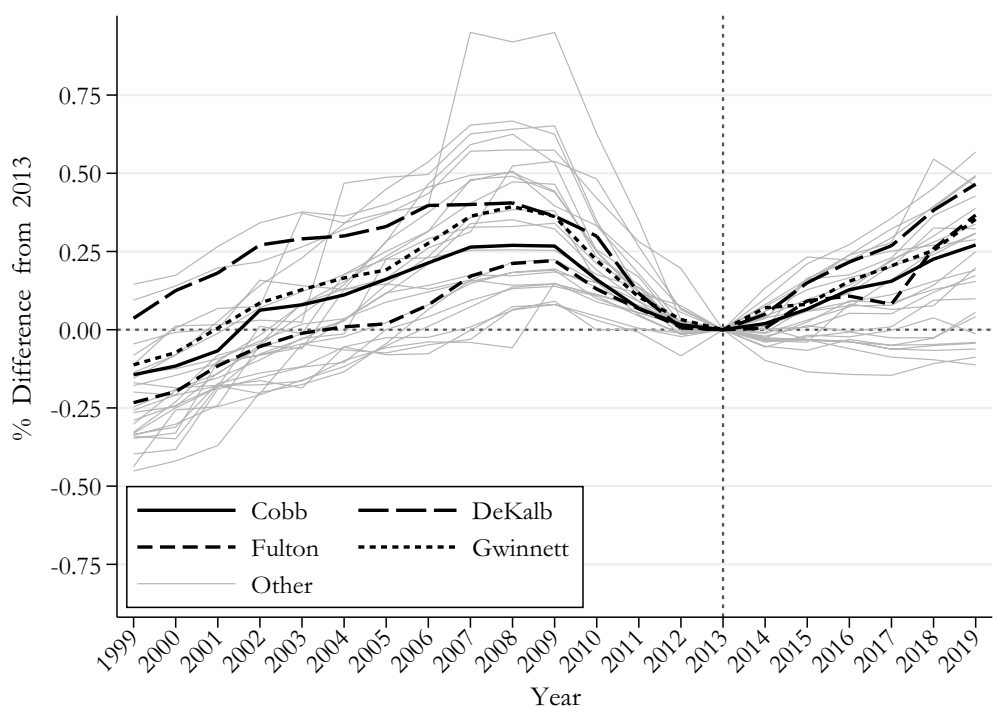

(a) Percent difference from year prior to announcement (2013)

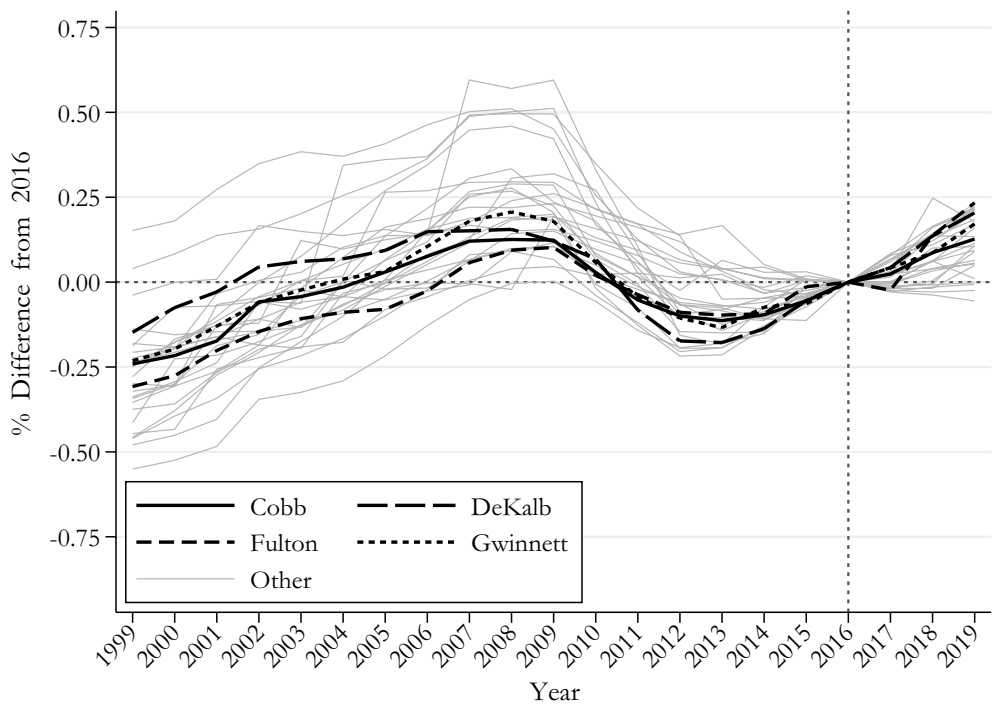

(b) Percent difference from year prior to opening (2016)

Fig. 2 County Assessed Value per Acre (1999-2019), Percent Difference from 2013 and 2016. Cobb's trajectory is not abnormal among all metro-Atlanta counties before or after the stadium was announced (2014) or opened (2017). Atlanta's core counties in black 
Cobb property assessments likely would have evolved if the Truist Park development had not occurred.

Georgia counties are appropriate units of observation, as previous studies have used Georgia counties for estimating economic impacts of various interventions. ${ }^{5}$ The synthetic control method uses a set of relevant county characteristics to compare Cobb to a control group of all Atlanta MSA counties, except Fulton County, which received the inverse treatment of losing its baseball team. The procedure employs an objective matching algorithm using pre-treatment means of county characteristics to construct a synthetic Cobb that reflects the county's observed property assessment values from a weighted average of donor counties. It selects and weights donor counties that best reproduce observed Cobb values to minimize the root mean squared prediction error (RMSPE) during the pre-treatment period, where donor weights are positive and sum to one. ${ }^{6}$ Because each synthetic control derives from pre-stadium county characteristic means, any post-stadium divergence of the progression of the observed and counterfactual trajectories indicates a causal effect.

I use the annual assessed real dollar value per acre in the county as the outcome of interest for examining the impact of the Truist Park development on Cobb County, observing the both the level and annual percent changes in assessments. The assessment level is important for estimating the aggregate impact on the County's tax digest to contribute to the general fund; however, because of Cobb's high property values in the region, a limited number of counties are likely to be appropriate donors. Therefore, I also observe annual percent changes in property assessments, which normalize values across counties to provide the opportunity for more counties to serve as donors and ensure that the comparisons are not an artifact of a limited donor pool. Observing yearly changes is also useful for assessing the growth impact of the stadium development on assessment values.

The sample period extends from 1999 to 2019, which ranges from earliest year for which county millage rates are available from the Georgia Department of Revenue to the year before the COVID-19 pandemic disrupted the economy. 2000 is the earliest observed year for the percent annual change estimates. The announcement and opening of the stadium provide two potential treatments identified in previous studies that may have influenced Cobb property values. The announcement treatment begins in 2014, the first year Cobb property was assessed following the surprise announcement of the stadium in November 2013. The opening treatment begins in 2017: the stadium opened in April of that year and hosted all 81 regularseason home games that season and all successive years. Thus, the sample includes

\footnotetext{
5 Hall, Matti and Zhou (2020) observes Georgia counties to examine the economic impact city-county consolidations. Several studies (Feddersen and Maennig 2013a, b; Hotchkiss, Moore and Zobay 2003; Hotchkiss, Moore and Rios-Avila 2015) use Georgia counties to estimate the economic impact of Atlanta hosting the 1996 Summer Olympic Games. Similar to this analysis, Bradbury (2021) uses Atlanta MSA counties to examine the impact of Truist Park on County sales tax revenue.

${ }^{6}$ I use the nested optimization procedure provided by Abadie, Diamond and Hainmueller (2011) to weight the relative importance of county characteristics for selecting and weighting donors in order to construct the synthetic controls reported in this analysis.
} 
15 (announcement) or 18 (opening) pre-treatment observations, which correspond to six or three post-treatment observations, respectively.

I use several characteristics associated with local property values as covariates to select donors and weights among control MSA counties. The natural log of income per capita measures the wealth of county residents. Land area accounts for the size of the county, which affects the amount of taxable land and government obligations for county services. The percent acreage devoted to commercial activity, as defined by the Department of Revenue in annual property assessments, accounts for the commercial use of land. Population density measures residential agglomeration and reflects the rural/urban nature of the county. The millage rate accounts for the property tax burden and services provided by the county governments. Because millage rates may differ across cities within counties, I use the millage rate of unincorporated areas. I include the Federal Housing Finance Agency (FHFA) House Price Index value for each county to reflect within-county changes in house prices over time. ${ }^{7}$ I also include distance of the county's government seat from Turner Field in downtown Atlanta as a covariate to account for distance from Atlanta's main employment center and transportation access in the county.

I employ the common practice in synthetic control method studies of including several lagged observations of the pre-treatment outcome (assessment value per acre) to account for co-movement among unobserved factors across counties. Matching units on pre-intervention outcomes controls for heterogenous responses to unobserved factors, because units that co-move for reasons not captured by observable county characteristics likely follow similar trajectories prior to the treatment (Cunningham 2021). I include the mean of assessed value per acre for the entire pre-treatment period (1999/2000-2013 for the announcement treatment or 1999/2000-2016 for the opening treatment) and the value per acre of the first pretreatment year (1999/2000), the middle pre-treatment year (2006 or 2008), and the final pre-treatment year (2013 or 2016).

Table 2 reports the pre-treatment means of county characteristics for Cobb, synthetic Cobb, and the mean of all control counties for the announcement and opening treatments. The comparisons demonstrate that the synthetic Cobb characteristics for both potential treatments are more similar to Cobb than the means of all control counties, and thus likely provide a superior counterfactual expectation of Cobb's post-stadium-treatment outcomes.

\section{Results}

Figure 3 maps observed and synthetic property assessment values for Cobb County before and after the announcement and opening treatments. I include the announcement and opening synthetic controls on the same graphs for both observed

\footnotetext{
7 The FHFA House Price Index, developed by Bogin, Doerner and Larson (2019), measures movement of single-family house prices in a county using repeat sales with a base year of 2000 (Federal Housing Finance Agency 2021).
} 


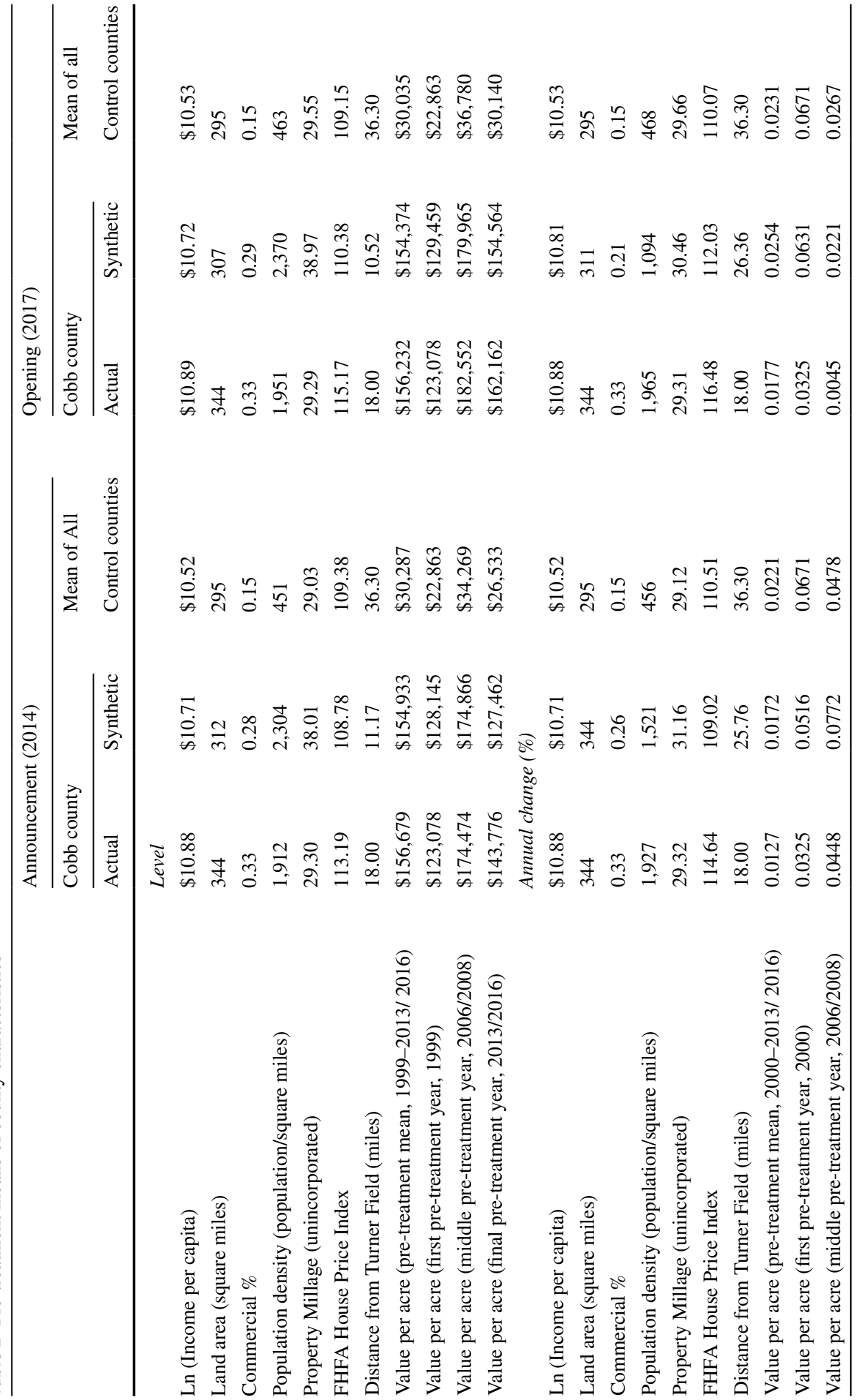




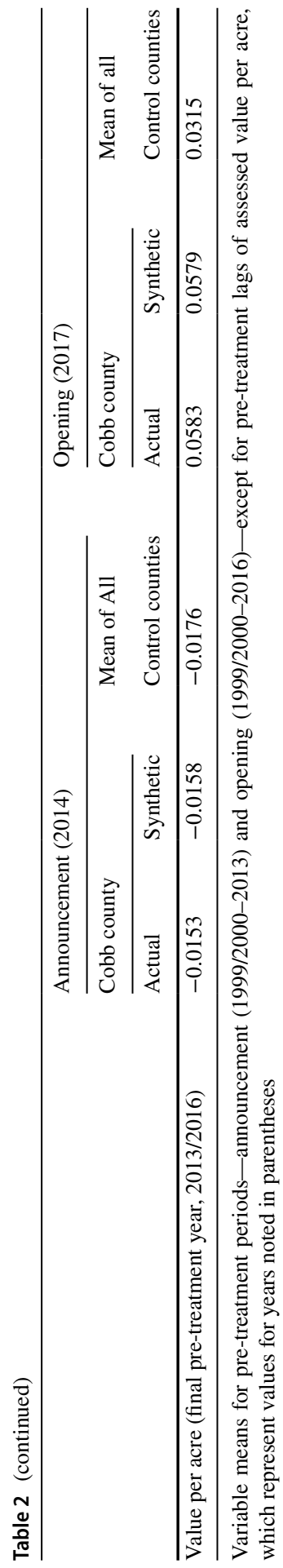




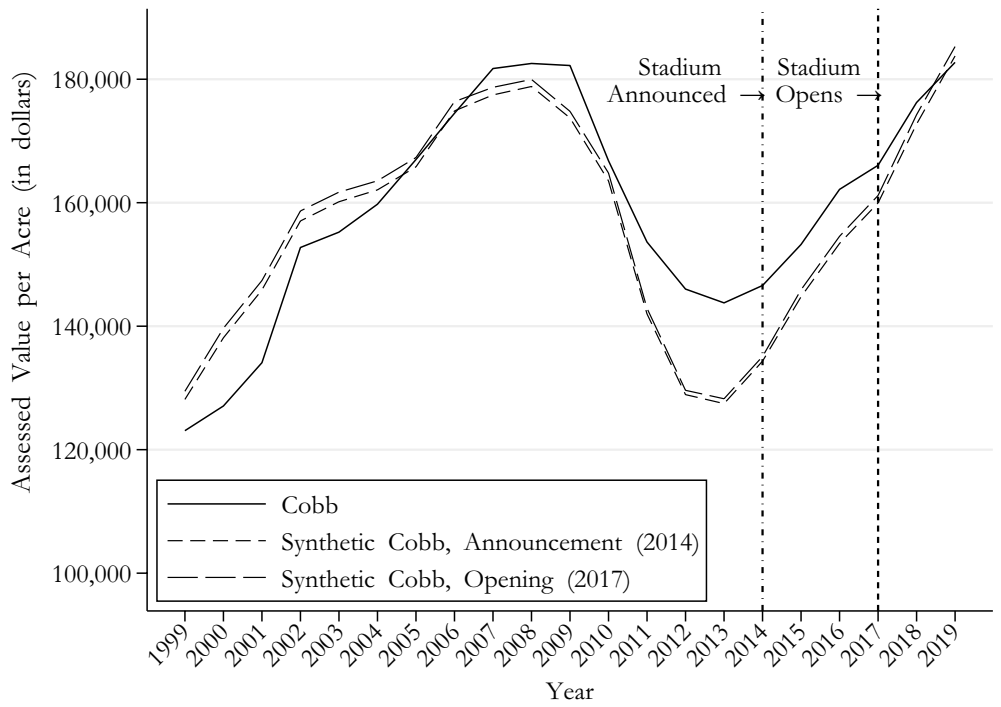

(a) Property Assessments

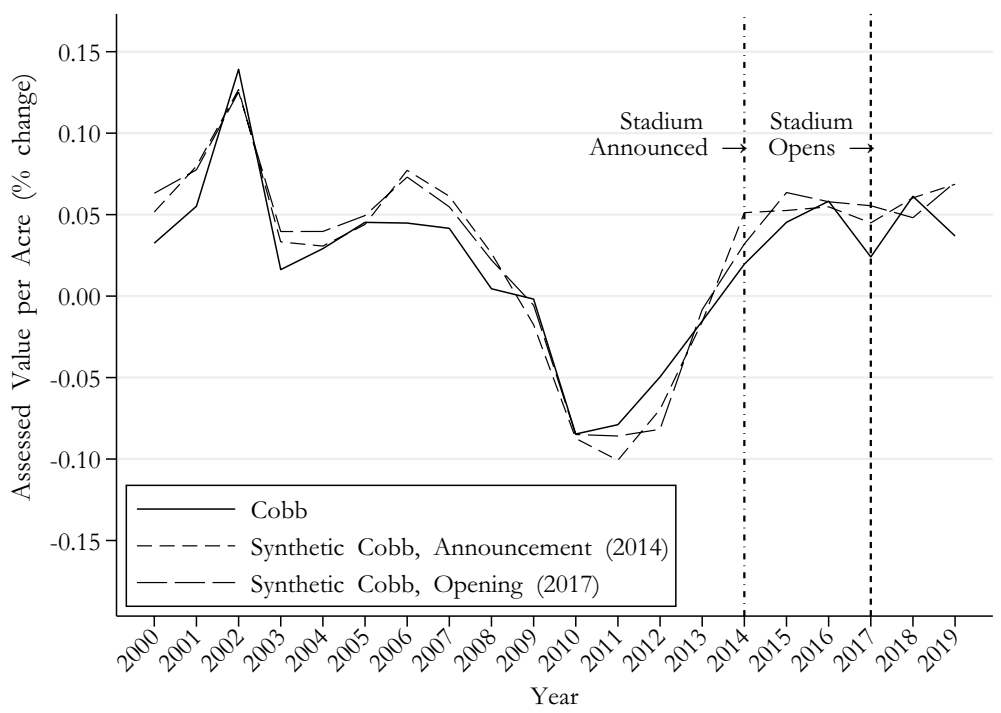

(b) Annual Change in Property Assessments (\%)

Fig. 3 Observed and Synthetic Property Assessment Values in Cobb County (1999-2019). Synthetic Cobb comparisons using announcement and opening treatments for property assessment levels (a) and annual percent changes (b)

outcomes, which shows the respective pre-treatment covariate means produce similar synthetic Cobb assessment levels and changes. Though observed and synthetic Cobb property values do not overlap precisely before or after the treatments, they 
Table 3 Donor and covariate weights

\begin{tabular}{|c|c|c|c|c|}
\hline & \multicolumn{2}{|l|}{ Level } & \multicolumn{2}{|c|}{ Annual change $(\%)$} \\
\hline & Announcement & Opening & Announcement & Opening \\
\hline Donor counties & \multicolumn{4}{|l|}{ Donor weights } \\
\hline Carroll & & & & 0.410 \\
\hline Clayton & & & 0.081 & \\
\hline DeKalb & \multirow[t]{3}{*}{0.754} & \multirow[t]{3}{*}{0.785} & 0.125 & 0.060 \\
\hline Fayette & & & & 0.307 \\
\hline Forsyth & & & 0.259 & 0.241 \\
\hline Gwinnett & 0.246 & 0.215 & 0.536 & 0.352 \\
\hline Covariates & \multicolumn{4}{|c|}{ Covariate Weights } \\
\hline Ln (Income per capita) & 0.0011 & 0.0473 & 0.0214 & 0.0525 \\
\hline Land area (square miles) & 0.0010 & 0.0005 & 0.3912 & 0.0556 \\
\hline Commercial \% & 0.0020 & 0.1355 & 0.0071 & 4.94E-05 \\
\hline Population density (population/square miles) & 0.0096 & 0.0496 & 0.0081 & 0.0023 \\
\hline Property millage (unincorporated) & 0.0002 & 0.0003 & 0.0646 & 0.0217 \\
\hline FHFA house price index & 0.0007 & 0.0360 & 0.0014 & 0.0147 \\
\hline Distance from turner field (miles) & 0.0006 & 0.0146 & 0.0473 & 0.0160 \\
\hline Value per acre (pre-treatment mean) & 0.5723 & 0.1770 & 0.0245 & 0.0099 \\
\hline Value per acre (first pre-treatment year) & 0.1808 & 0.0212 & 0.1632 & 0.0365 \\
\hline Value per acre (middle pre-treatment year) & 0.1665 & 0.3286 & 0.0037 & 0.0049 \\
\hline Value per acre (final pre-treatment year) & 0.0651 & 0.1895 & 0.2676 & 0.7859 \\
\hline Pre-treatment RMSPE & $\$ 8,738$ & $\$ 8,867$ & 0.0178 & 0.0175 \\
\hline
\end{tabular}

Donor weights reflect the relative contribution that each county contributes to synthetic Cobb. Covariate weights reflect each variable's relative contribution to the selection of donor counties. RMSPE is the pretreatment prediction error of the synthetic control

follow similar trajectories that reflect the progression of Cobb property assessments. The observed and synthetic values do not diverge following the stadium announcement or opening, which is not indicative of a treatment effect. For levels, the small deviation between observed and synthetic property values (predicted gap) narrows, rather than deviates, during the post-treatment periods, which is consistent with a negative treatment effect; however, the magnitude of the deviation is not statistically significant (see Fig.4 and the associated discussion in Sect. 4.1.1).

Table 3 reports the donor weights for counties used for generating synthetic Cobb property assessments and the weighting of county characteristics in selecting donors. The estimates of synthetic Cobb property assessment levels derive from weighting DeKalb between 75 and 79 percent, with the remainder attributed to Gwinnett. These counties are the most similar to Cobb in terms of proximity to Atlanta and Fulton. Though only two counties compose synthetic Cobb, the pre-treatment prediction error is small ( $\mathrm{RMSPE} \approx \$ 8,800$ ) relative to Cobb's pre-treatment mean value per acre of $\$ 155,000$. Abadie, Diamond and Hainmueller (2015) finds synthetic controls estimated from few units- even one unit-may offer a superior fit 


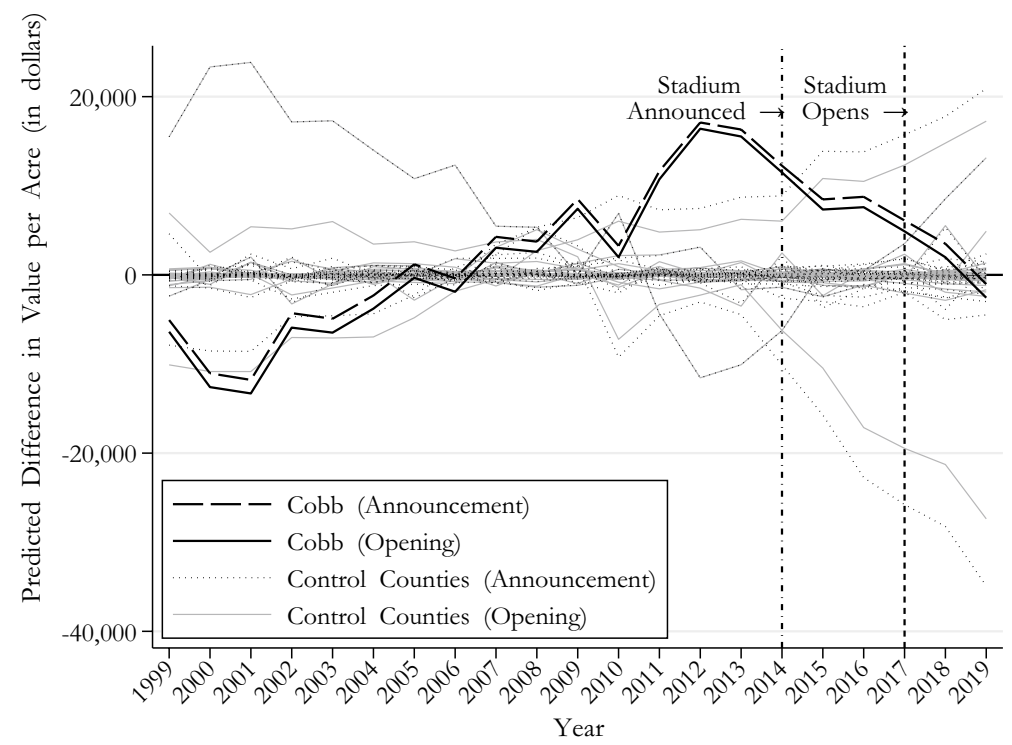

(a) Property Assessments

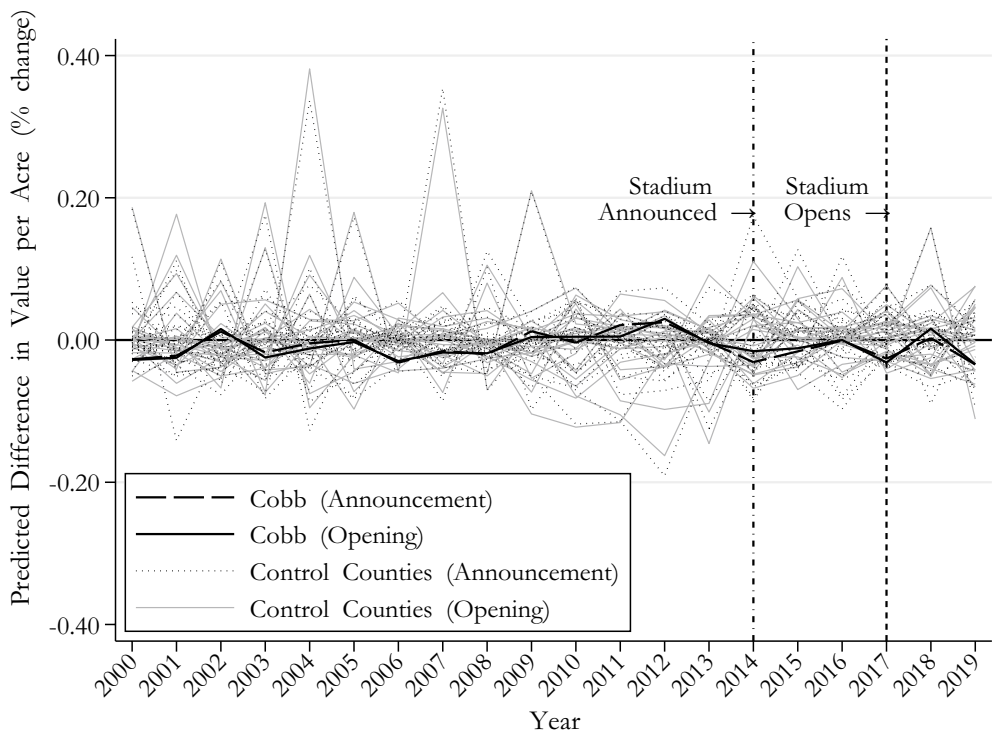

(b) Annual Change in Property Assessments (\%)

Fig. 4 In-Space Placebo Comparison. Lines map predicted gaps between observed and synthetic control assessment value per acre for Cobb and placebo treatments of control counties for announcement and opening treatments for property assessment levels (a) and percent annual change (b). Predicted gaps are not indicative of treatment effects 
to the control sample average. As I demonstrate further in Sect. 4.1.3, Cobb and its donor counties exhibit similar co-movement.

The synthetic controls for annual percent changes in assessments similarly use DeKalb and Gwinnett as donors, but include other counties as well. Clayton and Forsyth are selected as additional donors using the announcement pre-treatment means. Carroll, Fayette, and Forsyth are the additional donors selected using the opening pre-treatment means.

For both outcomes and treatments, covariate weights show that pre-treatment outcome lags play a significant role in selecting donors, which is consistent with county property values in the metro-Atlanta area moving together.

\subsection{Robustness}

A concern with synthetic control comparisons is that the synthetic estimate may be sensitive to donor selection and weighting from spurious correlations during the pre-treatment period that result in post-treatment trajectory divergences reflecting model design or post-treatment exogenous shocks to donors rather than a treatment response. Abadie (2021) suggests a series of robustness checks that evaluate the validity of the synthetic control in matching observed outcomes and sensitivity of the estimates. This is particularly important when reporting null results, to ensure than non-findings are the product of a lack of effect rather than poor study design.

\subsubsection{In-space placebo test}

The most common robustness evaluation presented in synthetic control method comparisons is the in-space placebo test, in which placebo treatments are assigned to untreated control units to produce a synthetic control for each control unit. The predicted gaps of the control units are compared to the predicted gap estimated for the actual treated unit. A relatively larger post-treatment predicted gap for the treated unit suggests that the estimated divergence reflects a treatment effect. I do this by estimating synthetic controls for each control county (all Atlanta MSA counties except Fulton) in separate estimates by reassigning placebo treatments for the stadium announcement and opening using the same county characteristics. If there is a treatment effect from the Cobb stadium, then the predicted gap between observed and synthetic Cobb following the treatments should be extraordinarily large relative to placebo counties that did not receive the stadium-treatment.

Figure 4 maps the predicted gaps between observed and synthetic assessed values for Cobb and all placebo-treated control counties. Cobb's deviation does not appear notably different from other counties, which is not supportive of a stadium-treatment effect. There is no exceptional change in Cobb property assessment levels as Cobb's predicted gap shows a gradual rise and fall that does not correspond to the stadium's announcement or opening. The predicted gaps follow similar trajectories, which indicates little difference between the announcement and opening treatments. The predicted gaps for percent annual changes are not exceptional in comparison to control counties, and no post-treatment deviations are obvious. 
Table 4 Cobb post-/pre-stadium RMSPE Ratios

\begin{tabular}{lllll}
\hline & Level & & \multicolumn{2}{l}{ Annual Change (\%) } \\
\hline & Announcement & Opening & Announcement & Opening \\
Post/Pre & 0.87 & 0.38 & 1.26 & 1.61 \\
$\begin{array}{l}\text { RMSPE } \\
\text { Ratio }\end{array}$ & & & & \\
$\begin{array}{l}\text { Cobb's rank } \\
\text { among } \\
\text { control } \\
\text { counties }\end{array}$ & 25 & 27 & 10 & 8 \\
\begin{tabular}{l}
$P$-value \\
\hline
\end{tabular} & 0.89 & 0.96 & 0.36 & 0.29 \\
\hline
\end{tabular}

Ratios of post-treatment and pre-treatment RMSPEs in placebo tests indicate Cobb's post-stadium deviations are not extraordinary in comparison to the 27 Atlanta MSA control counties

Abadie, Diamond and Hainmueller (2010) proposes a test statistic using the post-/pre-treatment ratio of the RMSPEs from the placebo test, which estimates the likelihood of a true treatment effect by ranking the ratios of the treated and control units. If the ratio of the treated unit is extremely high among placebo-treated units in a permutation distribution of ratios, it can be identified as statistically-significant according to standard p-value thresholds for hypothesis rejection. Table 4 reports that Cobb's post-/pre-stadium ratios have p-values well above 0.05, which confirms that Cobb's experience is not exceptional among metro-Atlanta counties and is consistent with the null hypothesis of no stadium-treatment effect on property assessments.

\subsubsection{In-time placebo test}

Synthetic control donor weights are selected based on the pre-intervention means of unit characteristics. If co-movement between treated and untreated units does not persist during the post-intervention period for reasons unrelated to the treatment, then the synthetic control is not a valid counterfactual outcome for comparison. A real-world post-treatment comparison is unobservable by nature; however, pretreatment comparisons between observed and synthetic outcomes may demonstrate the predictive ability of the characteristics in constructing a valid synthetic control. Abadie, Diamond and Hainmueller (2015) suggests a falsification test for validating the characteristics used for selecting the synthetic control by backdating the treatment timing to several periods before the actual treatment was implemented. If the quantity of pre-treatment observations is sufficiently large, setting an artificial premature placebo-treatment prior to the true treatment implementation permits observing how the synthetic control follows the observed output from pre-placebotreatment means after the placebo treatment while the true outcome of the treated unit remains observable. The in-time placebo test constructs a synthetic control from means of the pre-placebo-treatment characteristics. If the post-placebo-treatment observations estimate a synthetic control that shares a similar trajectory to observed outcomes prior to the treatment, it provides confidence that the synthetic control is 
an accurate projection of property assessments after the stadium was announced or opened.

I select 2010 as the beginning for the artificial premature placebo-treatment, which is four years prior to the earliest possible treatment effect from the stadium announcement and permits eleven pre-placebo-treatment observations. Weights are selected from pre-2010 means, rather than pre-2014 or pre-2017 means, to minimize RMSPE during the pre-placebo-treatment period. I use the same county characteristics to select county donors and weights from the same pool of control counties, with the exception of the pre-intervention assessment values per acre, which are the first (1999/2000), middle (2004), last (2009), and mean (1999/2000-2009) of the preplacebo-treatment period. For property assessment levels, the premature treatment results in the selection of the same donor counties and similar weights for DeKalb (0.70) and Gwinnett (0.30) as the true announcement and opening treatments. For annual percent changes, the matching algorithm selects donor counties (weight) of Clayton (0.05), DeKalb (0.49), Forsyth (0.31), Gwinnett (0.09), and Meriwether (0.06). Only the latter county was not selected using the announcement and opening treatments (Table 3).

Figure 5 reports the synthetic Cobb estimated using the 2010 placebo treatment in comparison to Cobb and synthetic controls estimated using the announcement and opening treatments. The premature placebo-treatment produces a synthetic Cobb that matches the progression of Cobb property assessment levels prior to the announcement and opening treatments and into the post-treatment period (5a). Also, the synthetic control generated by the premature placebo-treatment closely matches the synthetic controls generated from the announcement and opening treatments. The path of the placebo synthetic control for annual percentage change (Fig. 5b) does not follow the announcement and opening synthetic controls as closely as it does for the assessment level, but its trajectory is similar to the other synthetic controls and observed property assessments.

Thus, the similarity in post-stadium-treatment trajectories between synthetic and observed assessment values estimated from the premature placebo-treatment reinforces the predictive power of the model and provides credibility in the covariate characteristics used to construct the synthetic controls employed for post-stadiumtreatment counterfactual comparisons.

\subsubsection{Leaving out donors re-analysis}

As a further test of the robustness of findings to study design, Abadie (2021) recommends a leave-one-out re-analysis that estimates alternate synthetic controls after omitting selected donors to observe how specific control units may influence the synthetic control. If excluding a particular donor substantially alters the post-treatment trajectory of the synthetic control, it suggests that the donor may have experienced other interventions or unobserved idiosyncratic post-treatment shocks that unduly alter the synthetic control's trajectory rather than the treatment. Figure 6 presents estimates of alternate synthetic controls when the selected donors are omitted from the donor pool of control counties using the announcement treatment. Re-analyses using the opening treatment (not reported) are similar. 


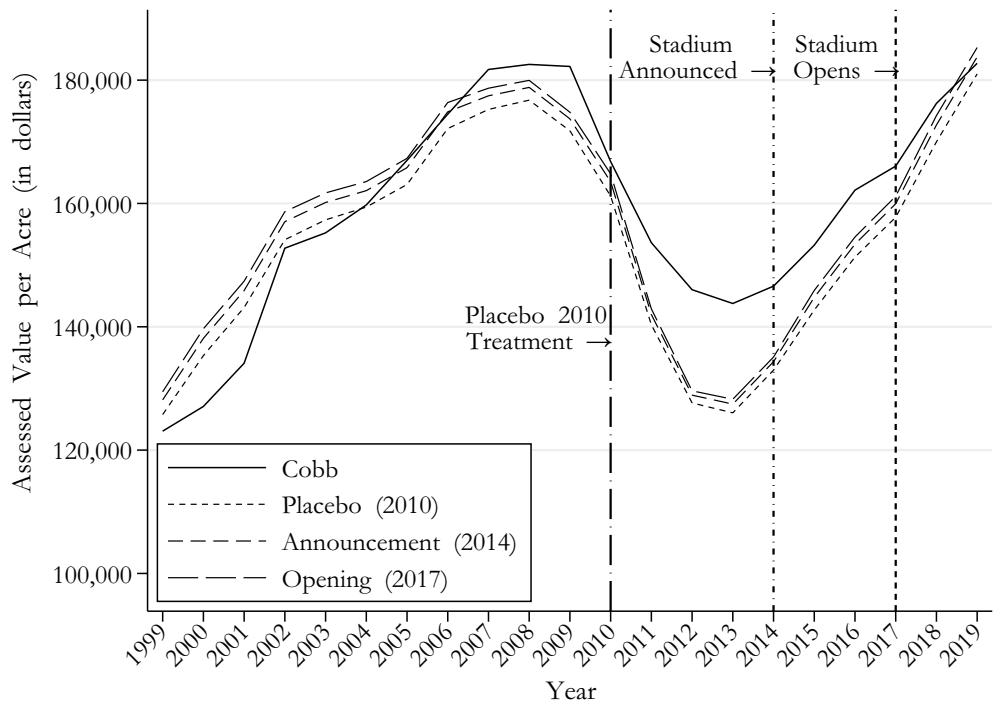

(a) Property Assessments

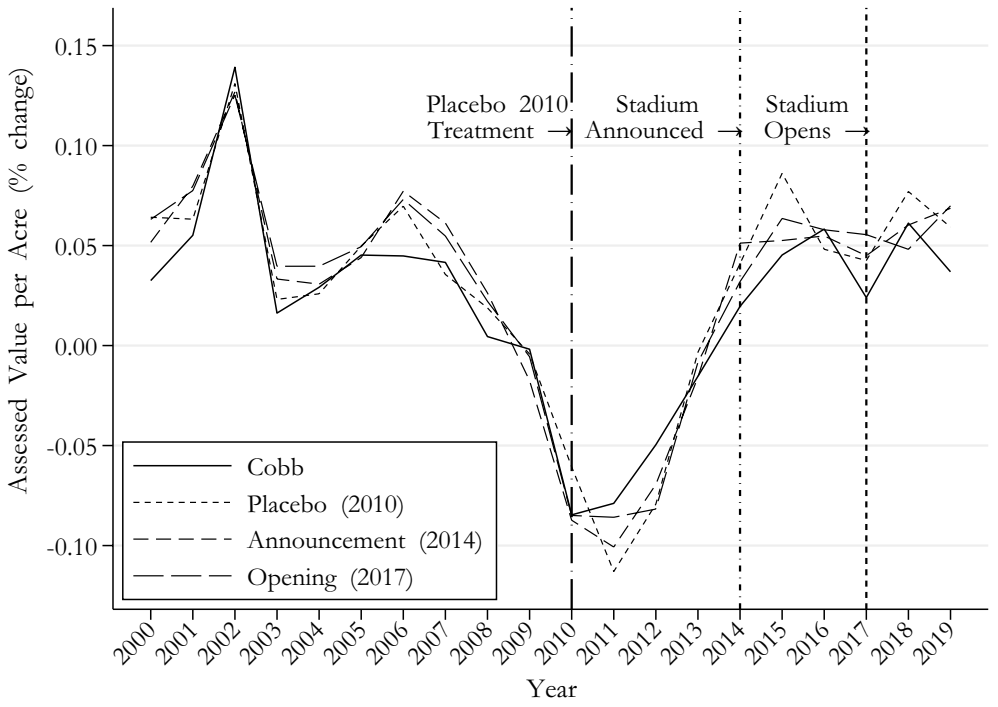

(b) Annual Changes in Property Assessments (\%)

Fig. 5 In-Time 2010 Placebo Treatment. Synthetic Cobb generated from premature 2010 placebo treatment, using pre-2010 covariate means, closely follows observed Cobb property assessments (a) and percent annual changes in property assessments (b) before and after stadium-treatments. The synthetic control is similar to synthetic controls estimated using pre-intervention means for announcement (2014) and opening (2017) treatments 


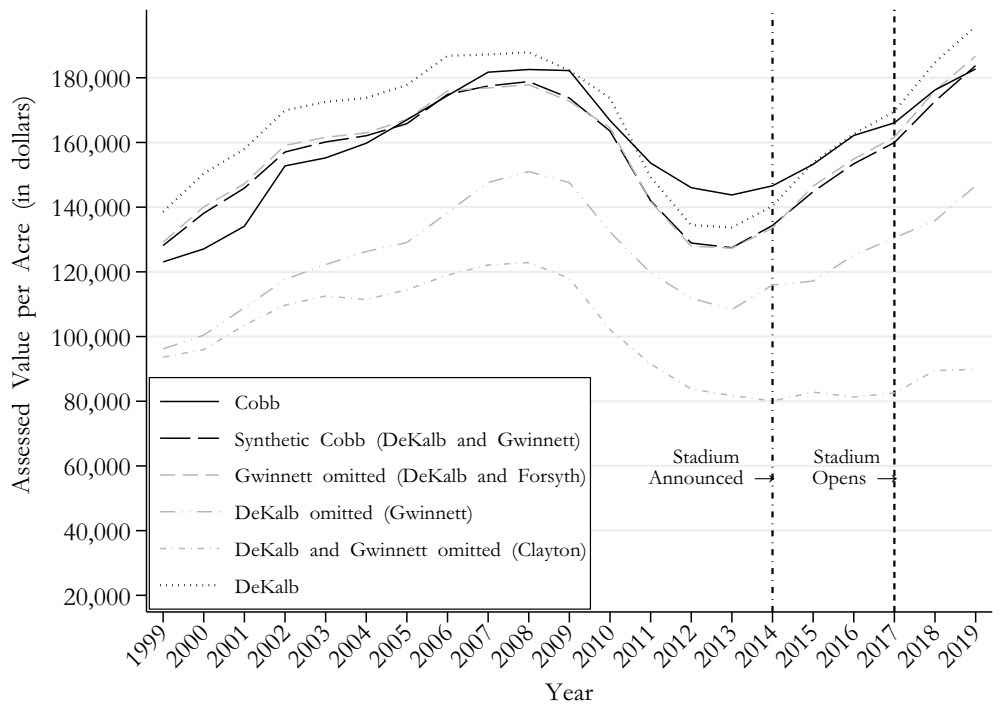

(a) Property Assessments

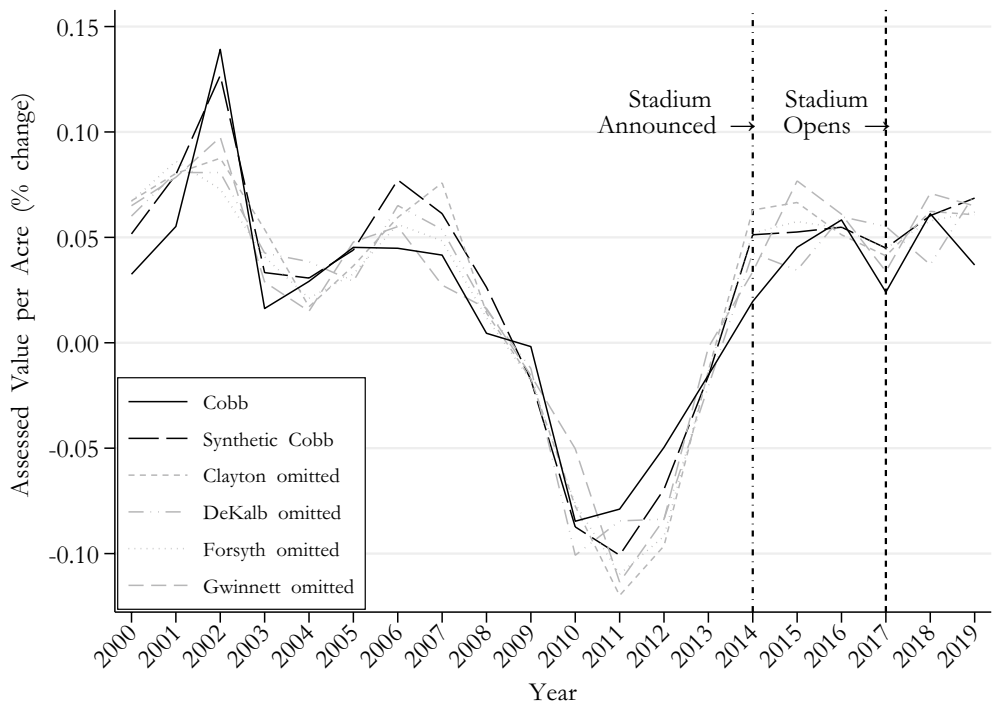

(b) Annual Changes in Property Assessments (\%)

Fig. 6 Leave Out Donors Re-Analysis (announcement treatment, 2014). Alternate synthetic controls omitting originally-selected donor counties. For property assessment levels (a), excluding Gwinnett produces a nearly identical synthetic control, while excluding DeKalb generates a less similar synthetic control that co-moves with Cobb. For annual changes in property assessments (b), excluding selected donors produces synthetic controls similar to synthetic Cobb from original donors 
For property assessment levels (6a), the comparison demonstrates that DeKalb (in particular) and Gwinnett are influential in producing a synthetic control that resembles the progression of Cobb's assessment values, and removing one or both counties from the donor pool produces worse pre-treatment fits. This is expected: because the matching algorithm selects a weighted average of the counties that best reflect pre-treatment outcomes, and both counties have suburban residential and commercial environments similar to Cobb. Omitting DeKalb results in Gwinnett being the sole donor, which exhibits co-movement similar to Cobb, though with consistently lower property values. Omitting Gwinnett, the donor with the lesser weight, produces a synthetic control from a weighted average that is 92 percent DeKalb and eight percent Forsyth. The synthetic controls are similar to the synthetic Cobb property assessments generated from DeKalb and Gwinnett, though their fits are slightly worse $(\mathrm{RMSPE} \approx \$ 9,400)$.

The strong importance of DeKalb is unsurprising given that it is adjacent to the City of Atlanta like Cobb-a small portion of Atlanta extends into DeKalb-however, the matching algorithm continues to select another donor county to construct the synthetic Cobb along with DeKalb, even after selected replacement control counties are dropped from the donor pool. Omitting Forsyth in addition to Gwinnett results in the selection of Douglas (announcement) or Cherokee (opening), and excluding those replacement donors results in the selection of Henry as the replacement donor. In all cases, the replacement donor has a weight of approximately six to eight percent, with DeKalb receiving the remaining weight. For comparison, Fig. 6 includes DeKalb's observed assessment values over time, which fluctuates with Cobb quite closely, but the synthetic control that includes an additional more-distant suburban county better matches Cobb. DeKalb has a larger footprint within Atlanta's outer-belt expressway - an area colloquially known as "inside the Perimeter" to delineate its urban character within the metro area-than Cobb, which is more urban in its development than areas outside the Perimeter, like most of Cobb. Thus, a combination of DeKalb and another suburban county provides a better counterfactual of Cobb than DeKalb alone, which likely reflects Cobb's more suburban character as it extends farther from central Atlanta than DeKalb.

Omitting both DeKalb and Gwinnett counties from the control units results in Clayton County as the sole donor, which co-moves with Cobb to a lesser extent than the other synthetic controls, and has much lower property values. The re-analysis demonstrates that DeKalb and Gwinnett are important contributors the synthetic control of Cobb property assessments, because their assessments co-move closely with Cobb's. The more important finding is that neither county's exclusions are suggestive of post-treatment interventions or shocks driving the trajectory of synthetic Cobb constructed from the counties.

Synthetic control estimates of annual changes in property assessments are less sensitive to donor omissions than assessment levels. In all cases, the alternate synthetic controls resemble observed and synthetic property assessments using the original donor pool.

Overall, the re-analyses confirm that there are no large idiosyncratic shocks in control counties that appear to be influencing the counterfactual estimates unduly. The strong co-movement between assessed property values in Cobb and donor 
counties indicates that it is appropriate to use a weighted average of the selected metro-Atlanta county donors to construct a synthetic Cobb to evaluate post-stadium changes in Cobb property values. Cobb's changes in property assessments appear to follow a trajectory of two of its suburban neighbors close to Atlanta's core, which is also demonstrated in comparisons of percentage changes over time displayed in Fig. 2.

\subsubsection{Sensitivity to covariate selection}

Objectivity and transparency are important attributes of the synthetic control method, because they limit the opportunities for researcher manipulation through specification searching. The method constructs its counterfactual outcome from formal objective criteria prior to the post-treatment period, and the weights of donors and the characteristics used to select donors are explicit. However, it remains possible for researchers to report findings selectively that support favored hypotheses. In order to address potential researcher bias when presenting results, Ferman, Pinto and Possebom (2020) recommends reporting alternate synthetic controls estimated from multiple covariate configurations to demonstrate the robustness of synthetic control estimates. Following the authors' example, I estimate multiple synthetic controls using several pre-intervention outcomes-all years individually, even years, odd years, mean of all years - as well as including only county characteristics or only pre-intervention outcomes. Figure 7 reports the estimates from alternate configurations, using the announcement treatment. Synthetic controls for assessment values using the opening treatment (not reported) are similar.

For property assessment levels, the weighing algorithm selects the same donors and weights to produce synthetic controls identical to the selected synthetic Cobb reported in Fig. 3a in all but once case. The exception results when only the pretreatment county characteristics are used for matching; thus, it is unsurprising that it produces a less similar synthetic control, and it co-moves similar to the observed and other synthetic Cobb property assessments. Differing covariate configurations for annual changes in property assessments produces more variation in synthetic controls; however, the deviations from the selected synthetic and observed Cobb property assessments are slight, and their trajectories do not indicate a treatment effect. Thus, synthetic control construction does not appear to be sensitive to covariate characteristics used for donor selection and weighting.

\section{Discussion and implications}

\subsection{Fiscal Impact}

While Cobb property assessment values have increased since the stadium was announced and opened, the relative growth among nearby counties is not indicative of a causal effect. A positive impact from the Cobb stadium development is not evident in before-and-after comparisons with all Atlanta-MSA counties (Fig. 2) or more precise synthetic controls (Fig. 3). The comparisons reveal that Cobb's 


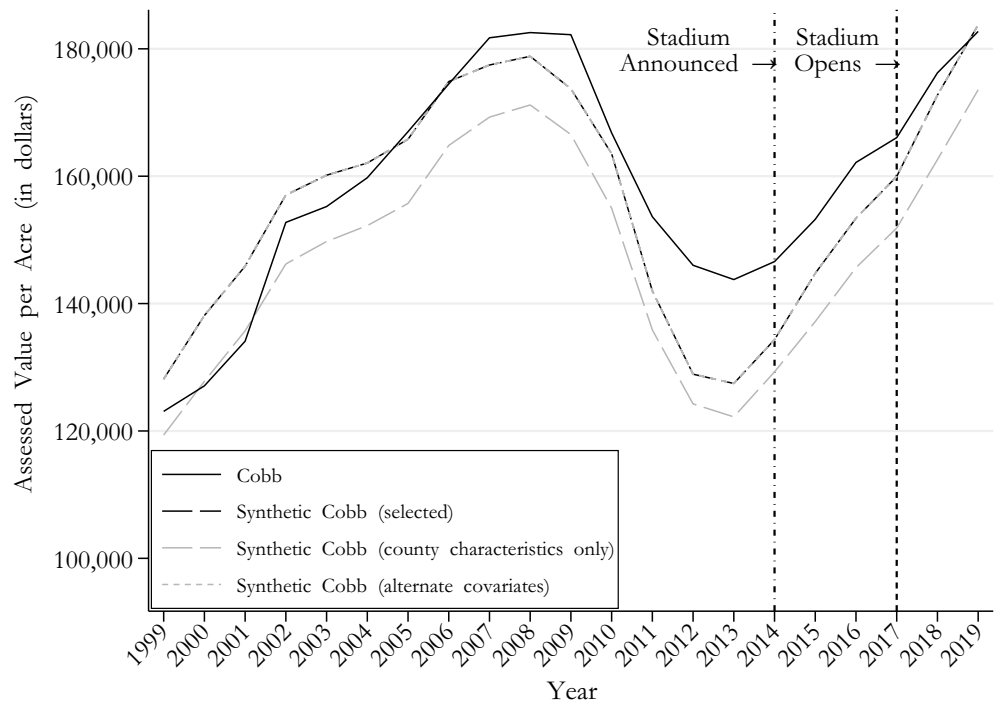

(a) Property Assessments

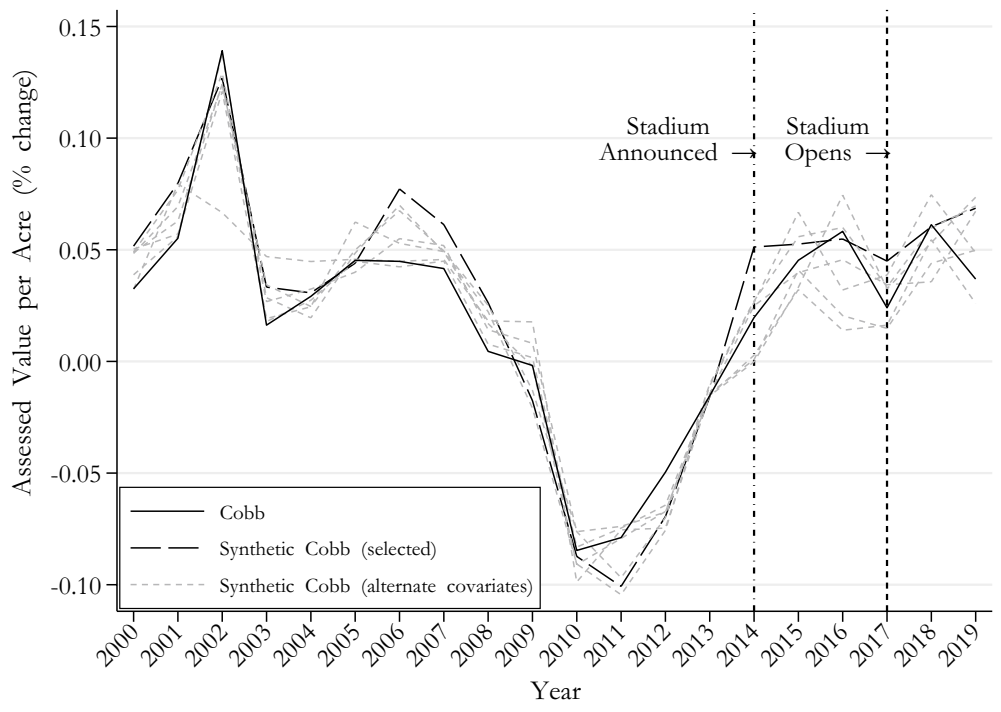

(b) Annual Changes in Property Assessments (\%)

Fig. 7 Alternate Covariates (announcement treatment, 2014). Alternate synthetic controls generated from different covariate configurations: multiple pre-treatment outcome lags, county characteristics only, and pre-treatment outcome lags only. For property assessment levels (a), synthetic controls are identical to the selected model, with the exception of county characteristics. For annual changes in property assessments (b), synthetic controls are similar to the selected model 
progression of property assessments has been ordinary for the Atlanta area, and the estimates are robust to standard sensitivity tests. Thus, the stadium development has not resulted in increased property tax revenue through greater assessments as advocates predicted.

One possible objection to the inference that the stadium has been ineffective at boosting community welfare drawn from the estimated non-effect is that no observable effect should be expected from this relatively small development project at the county level, especially in a jurisdiction as large and prosperous as Cobb. While such concern may seem reasonable from an effect identification standpoint; from a practical policy perspective, it is irrelevant. Like most stadium proposals, Truist Park advocates vociferously claimed that the stadium would have a significant fiscal impact on the County. Commissioner Lee predicted the return on investment to taxpayers explicitly in those terms.

The average resident is going to pay \$26 a year for millions of dollars in returned investment and the benefit associated with that. I think it's a good investment by the Cobb County government on behalf of the taxpayers to spend \$26 to create the returned investment we're going to get in economic growth, the continued job creation, the expansion of our economy and all the opportunity that it provides for us so I think that that is a good investment (Gillooly 2013b).

If the stadium enhanced community welfare, property assessment values should be exceeding expectations. The findings demonstrate that the stadium did not boost property tax revenue through rising assessments as promised. The County budgets close to $\$ 20$ million per year to fund its stadium obligations, which it must recoup through cuts in other service or increased taxes. ${ }^{8}$ Rather than cutting taxes, Cobb County increased its millage rate by 0.54 mills between 2013 and 2019, not including the 0.33 mills reallocated from park bond revenue to fund the stadium. ${ }^{9}$ These observations are not consistent with stadium producing a positive return on investment to the County.

The findings are consistent with more granular analyses of Truist Park's impact on economic activity, which do not identify strong economic effects from the stadium at sub-local levels. The stadium has not been associated with increased commercial property assessments in its host business district, which does not support the claim of substantial development externalities surrounding the ballpark (Bradbury 2022). There is evidence that the stadium-development increased County sales tax collections; however, the added revenue has not been sufficient to cover County subsidies and indicates substantial crowding out of other Cobb spending (Bradbury 2021). The examination of county-wide property values in this analysis offers a final

\footnotetext{
${ }^{8}$ Bradbury (2021) presents a breakdown of annual County budget obligations to fund the stadium. Typical annual funding obligations approach \$25 million before ANLBC contributes \$6.1 million in rent.

9 Cobb County's total county-wide non-school millage rate, which includes maintenance and operations, bond initiatives, and fire, increased from 10.91 mills in 2013 to 11.45 mills in 2019 (Georgia Department of Revenue 2020).
} 
channel through which the stadium might demonstrate net benefits-which includes non-pecuniary social benefits-flowing to Cobb taxpayers who funded the stadium. The consistent lack of impact in all analyses suggests that the stadium has not produced the projected boost in economic and non-pecuniary benefits to taxpayers.

Though the policy focus has been on the potential positive effect of the stadium, it is important to note that the comparisons do not identify a negative effect. The null findings also indicate that the added tax burden and/or negative externalities associated with the stadium do not appear to have been sufficient to dampen property assessments by a significant amount. Overall, the stadium may be a break-even proposition.

\subsection{Stadium spillovers and property values}

The findings are also applicable to the economics literature on stadium spillovers to host communities that ought to be reflected in property values, which has produced mixed findings. For example, Carlino and Coulson (2004) identifies increased residential rents from hosting NFL teams in host regions of varying size. The largest estimates are concentrated closest to central cities but extend to the entire metropolitan area, indicating that the quality-of-life spillovers of hosting a professional sports team may be spread over a wide geographic region due to the scope of fandom. The authors also identify a positive metropolitan area effect for hosing MLB teams that is stronger in suburban areas like Cobb County. This analysis similarly assesses the social benefits aspect over the entire county, which was pitched as a benefit when the project was introduced.

The non-positive estimates do not support an existence value effect from Cobb County hosting an MLB team. It is possible that existence benefits were already capitalized into Cobb property values from the team's and county's coexistence in metro-Atlanta. If so, Cobb taxpayers may be paying for a non-excludable benefit they were previously free-riding on. The stadium's impotence with respect to assessment values is consistent with findings of limited non-pecuniary social benefits from hosting professional sports teams.

\subsection{Voter perceptions}

Researchers also have used voting to evaluate non-excludable spillovers of professional sports teams on local residents-where voters can register preferences that are not captured in markets-however, empirical evidence regarding how communities perceive sports stadiums in referendums has been mixed. The lack of positive impacts on property assessments is consistent with subsequent Cobb election results, which may reflect county residents' perceptions of the stadium and team relocation benefits as they are distributed throughout the county.

Dehring, Depken and Ward (2008) examines referendum voting on an NFL stadium in Arlington, Texas, finding voter support for the stadium to be positively associated with estimated impacts on property values, but that homeowners in general were less likely to support stadium proposals. Coates and Humphreys (2006) finds 


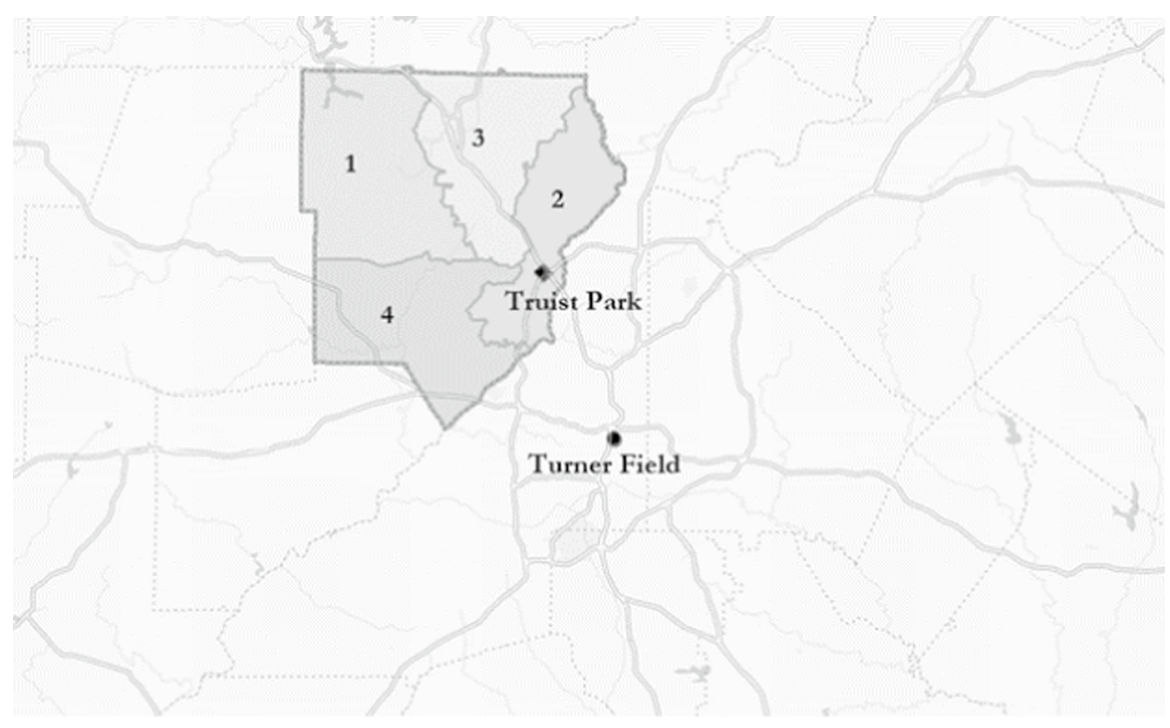

Fig. 8 Cobb County Board of Commissioners Districts

that voters who lived close to basketball (Houston, Texas) and football (Green Bay, Wisconsin) facilities were more likely to favor subsidies than voters living further away. In contrast, Ahlfeldt and Maennig (2012) finds voter support for local facilities to be stronger for soccer stadium sites further away from their location in Munich, Germany, indicating a NIMBY ("not in my back yard") preference associated with avoiding negative stadium spillovers. Similarly, Horn, Cantor and Fort (2015) finds support for a football stadium in Seattle, Washington to be weakest in close proximity to the stadium, while voters within easy driving access to the stadium were more likely to vote in support of the stadium.

Though Truist Park was not approved via a referendum, Cobb County's Board of Commissioners elections provide information about district-level and county-wide voter preferences for the project, because the project became a major focal point in subsequent campaigns. The five-member Cobb Board of Commissioners is composed of four members elected from geographic districts, and the Board Chair is elected county-wide. The Board of Commissioners approved a memorandum of understanding with ANLBC 4-1, with commissioners from Districts 1, 2, and 3 and the Chairman voting to approve, and District 4 Commissioner Lisa Cupid casting the dissenting vote. Figure 8 maps Cobb commissioner districts in relation to metroAtlanta. Truist Park is located in District 2, just across the Atlanta/Fulton County border. Districts 2 and 3 are situated in east Cobb, more closely connected to the stadium via Interstate-75 and Interstate-285. Districts 1 and 4 in west Cobb are less connected to the stadium through local interstates.

During the 2016 election, the stadium was the dominant campaign issue when the chief stadium deal advocate Chairman Lee faced his first re-election contest after the stadium was approved. Lee was challenged in a grassroots campaign by neophyte Mike Boyce who declared the election to be "a delayed referendum" on the stadium, 
with Lee highlighting the economic development benefits from bringing the stadium to Cobb (Gargis 2016). The theme of the race was well documented by the media.

Lee is running on his legacy of bringing the Atlanta Braves to Cobb County, a deal he secured by committing $\$ 400$ million in public money to build and maintain a new ballfield. In return, Lee says, the county will reap the benefits of $\$ 1.2$ billion in investment from the park and surrounding development. But Boyce's candidacy is drawing on a deep well of resentment over the deal, which was struck in secret without a public vote. ${ }^{10}$

Boyce defeated Lee with 65 percent of the vote in the Republican primary runoff, and he was unopposed in the general election. East Cobb District 2 Commissioner Bob Ott, who regularly touted the stadium's robust impact on the local economy in his district during his tenure (see epigraph), was re-elected that same year. Stadium opponent Commissioner Lisa Cupid was also re-elected as District 4's representative in 2016. District 3's representative was twice re-elected, in 2014 and 2018, and District 1's representative did not seek reelection.

Though candidate Boyce was critical of the stadium deal in 2016, Chairman Boyce became a strong stadium advocate after taking office, often speaking highly of the development as a driver of tax revenue. A local newspaper recounted his change of heart, commenting that "Boyce was effusive in his praise for Lee and the Braves-a dizzying turnaround from when he was knocking on voters' doors all over Cobb County, lambasting the project during his 2016 campaign" (Around Town 2019). Boyce would end up being defeated as Chairman in his 2020 re-election bid by District 4 Commissioner Cupid, who cast the lone dissenting vote against the stadium project in 2013.

Though the inferences researchers should draw from this general comparison are limited-particularly because representative democracy elections are not singleissue plebiscites - the results from Cobb's post-stadium elections are consistent with referendum results for other stadium projects. Districts 2 and 3 are located along the east Cobb transportation corridor with easy access to the stadium, and district voters re-elected their stadium-supporting representatives. District 4 voters in the southwestern part of the county did not punish their representative for her dissenting vote, and she was ultimately elected as Chairwoman in a county-wide election. Voter support for the stadium does not appear to be strong at the county-wide level, even though it may have stronger support in the local sub-communities (Districts 2 and 3) who may receive greater benefits from the stadium than the Cobb median voter. Voter preferences are also consistent with the stadium's lack of impact on countywide property values identified in this study.

\footnotetext{
10 The $\$ 400$ million references the total County debt issued, which includes a portion ANLBC repays to the County in annual installments, and thus does not accurately reflect the public burden of the subsidy (Lutz 2016). The public contribution in the initial agreement amounts to $\$ 300$ million.
} 


\section{Summary and conclusion}

Local governments frequently subsidize stadiums and arenas in order to host professional sports teams, which supporters often justify as worthwhile public investments that generate positive returns to the community through new economic activity and added quality-of-life benefits. This study examines the fiscal impact of a recent professional baseball team relocation and stadium project in Cobb County, Georgia using local property assessments. Though previous studies have not identified strong economic impacts from stadiums, the relocation of the area's baseball team from downtown Atlanta to a new suburban jurisdiction near a major highway junction offers the possibility of interjurisdictional inflows of new spending and residents into Cobb that are atypical among stadium developments.

Property assessments values ought to capture the capitalized value of economic development and social benefits that the stadium generates for the community. Increased assessment values should translate into increased property tax revenue for the County, and thus they provide a useful measure for evaluating the project's return on investment. This analysis employs the synthetic control method to identify the stadium's impact on local property assessments using metro-Atlanta counties with similar characteristics to construct counterfactual comparisons of Cobb property assessment values absent the stadium. The comparisons do not identify changes to Cobb property assessments that are exceptional among metroAtlanta counties. The findings contradict the claim that the stadium would generate a sufficient return on investment through County property tax revenue to more than recoup tax funding.

This study also contributes to the literature on the intangible social benefits of hosting professional sports teams, in which researchers estimate the existence value of teams that is not captured in market transactions. If the presence of a team boosts residents' quality of life through non-pecuniary spillovers, then these gains should manifest in property values. That Cobb property assessments progressed similar to other metro-Atlanta counties indicates that the social benefits of hosting the team in Cobb have not been not substantial.

In summary, Cobb stadium advocates predicted that the Truist Park/The Battery Atlanta development and associated MLB team relocation would be an economic "home run for Cobb," which would generate sufficient tax revenue through new economic activity to cover the County's investment in the project. The absence of any observable impact on property assessments does not support this contention. The failure of the Cobb stadium development is instructive to other potential stadium projects due to the fact that Truist Park was primed to succeed with a favorable location and associated mixed-use development. The findings indicate that even with these advantages, sports stadiums are unlikely to cover the costs of the public investments that they typically receive. 


\section{References}

Abadie A (2021) Using synthetic controls: feasibility, data requirements, and methodological aspects. J Econ Lit 59(2):391-425

Abadie A, Diamond A, Hainmueller J (2010) Synthetic control methods for comparative case studies: estimating the effect of California's tobacco control program. J Am Stat Assoc 105:493-505

Abadie A, Diamond A, Hainmueller J (2011) "Synth: Stata module to implement synthetic control methods for comparative case studies," Statistical Software Components S457334. Boston College Department of Economics

Abadie A, Diamond A, Hainmueller J (2015) Comparative politics and the synthetic control method. Am J Polit Sci 59:495-510

Abadie A, Gardeazabal J (2003) The economic costs of conflict: a case study of the Basque Country. Am Econ Rev 93:113-132

Ahlfeldt GM, Kavetsos G (2014) Form or function?: the effect of new sports stadia on property prices in London. J R Stat Soc Series A (Stat Soc) 177(1):169-190

Ahlfeldt GM, Maennig W (2010) Impact of sports arenas on land values: evidence from Berlin. Annal Region Sci 44(2):205-227

Ahlfeldt GM, Maennig W (2012) Voting on a NIMBY facility: proximity cost of an iconic stadium. Urban Affairs Rev 48(2):205-237

Around Town (2019) "Ex-chairman Lee grateful for stadium and his health," Marietta Daily Journal, April 11, https://www.mdjonline.com/opinion/around-town-ex-chairman-lee-grateful-for-stadi um-and-his-health/article_5e9d368e-5c7f-11e9-b2e1-67e8130d489c.html, (accessed May 14, 2021)

Athey S, Imbens GW (2017) The state of applied econometrics: causality and policy evaluation. J Econ Perspect 31(2):3-32

Bogin A, Doerner W, Larson W (2019) Local house price dynamics: new indices and stylized facts. Real Estate Econ 47(2):365-398

Bradbury JC (2021) "Sports stadiums and local economic activity: evidence from sales tax collections," https://papers.ssrn.com/sol3/papers.cfm?abstract_id=3802875, Manuscript

Bradbury JC (2022) The impact of sports stadiums on localized commercial activity: evidence from a business improvement district. J Reg Sci. https://doi.org/10.1111/jors.12560

Carlino G, Edward Coulson N (2004) Compensating differentials and the social benefits of the NFL. J Urban Econ 56(1):25-50

Carlino G, Edward Coulson N (2006) Compensating differentials and the social benefits of the NFL: reply. J Urban Econ 60:132-138

Coates D, Humphreys BR (2006) Proximity benefits and voting on stadium and arena subsidies. J Urban Econ 59(2):285-299

Coates D, Humphreys BR (2008) Do economists reach a conclusion on subsidies for sports franchises, stadiums, and mega-events? Econ J Watch 5(3):294-315

Coates D, Humphreys BR, Zimbalist A (2006) Compensating differentials and the social benefits of the NFL: a comment. J Urban Econ 60(1):124-131

Cunningham S (2021) Causal inference: the mixtape. Yale University Press, New Haven

Deere S (2021) "Years after opening day, Braves-Cobb stadium deal still under scrutiny," Atlanta Journal-Constitution, March 26, https://www.ajc.com/news/atlanta-news/years-after-opening-daybraves-cobb-stadium-deal-still-under-scrutiny/JQWOWCSRMNBHPA6DE4JF3J2SLU/, (accessed May 17, 2021)

Dehring CA, Depken CA, Ward MR (2007) The impact of stadium announcements on residential property values: evidence from a natural experiment in Dallas-Fort Worth. Contemp Econ Policy 25(4):627-638

Dehring CA, Depken CA, Ward MR (2008) A direct test of the homevoter hypothesis. J Urban Econ 64(1):155-170

Feddersen A, Maennig W (2013) Employment effects of the olympic games in Atlanta 1996 reconsidered. Int J Sport Finan 8:95-111

Feddersen A, Maennig W (2013) Mega-events and sectoral employment: the case of the 1996 olympic games. Contemp Econ Policy 31(3):580-603

Federal Housing Finance Agency (2021) "House price index," https://www.fhfa.gov/DataTools/Downl oads/Pages/House-Price-Index.aspx, (accessed September 17, 2021) 
Feng X, Humphreys BR (2012) The impact of professional sports facilities on housing values: evidence from census block group data. City Cult Soc 3(3):189-200

Feng X, Humphreys BR (2018) Assessing the economic impact of sports facilities on residential property values: a spatial hedonic approach. J Sports Econ 19:188-210

Fenn AJ, Crooker JR (2009) Estimating local welfare generated by an NFL team under credible threat of relocation. South Econ J 76(1):198-223

Ferman B, Pinto C, Possebom V (2020) Cherry picking with synthetic controls. J Policy Anal Manag 39:510-532

Gargis J (2016) “Tim Lee and Mike Boyce to go head to head on July 26," Marietta Daily Journal, May 25, https://www.mdjonline.com/news/tim-lee-and-mike-boyce-to-go-head-to-head-on-july-26/artic le_c622b1ce-2237-11e6-abf2-ffaee9ec233a.html, (accessed May 14, 2021)

Gargis J (2017) “The Braves in Cobb: A financial check 4 months into the season,” Marietta Daily Journal, August 19, https://www.mdjonline.com/news/b-the-braves-in-cobb-b-a-financial-check-4months-into-the-season/article_8cea70c6-8556-11e7-8cbb-b7e8ed4fc970.html, (accessed May 7, 2021)

Georgia Department of Revenue (2017) “Tax digest consolidated summary: how to interpret," https://dor. georgia.gov/document/publication/tax-digest-consolidated-summary-how-interpretpdf/download, (accessed March 6, 2020)

Georgia Department of Revenue (2020) "Property tax millage rates," https://dor.georgia.gov/local-gover nment-services/digest-compliance-section/property-tax-millage-rates, (accessed February 17, 2021)

Georgia Department of Revenue (2021a) "Appraisal procedure manual," https://dor.georgia.gov/appra isal-procedure-manual, (accessed May 21, 2021)

Georgia Department of Revenue (2021b) "Digest summaries," https://sso.dor.ga.gov/digestsummaries, (accessed April 22, 2021)

Georgia Department of Revenue (2021c) "Property tax - real and personal property - FAQ," https://dor. georgia.gov/property-tax-real-and-personal-property-faq-0, (accessed May 21, 2021)

Georgia Department of Revenue (2021d) "Property tax valuation: How is property assessed?," https://dor. georgia.gov/property-tax-valuation\#assessed, (accessed May 21, 2021)

Gillooly J (2013a) “Goreham 'surprised' by support for team Commissioner says she's 'shocked' by small number of residents opposing Braves' move to Cobb in 2017," Marietta Daily Journal, November 22, https://www.mdjonline.com/news/goreham-surprised-by-support-for-stadium-plan/article_ 42459b6e-4021-50f4-8a89-ebecfd5e4a5c.html, (accessed May 14, 2021)

Gillooly J (2013b) 'Lee predicts 'unanimous' Braves vote Chairman: 'small investment by residents' will translate to 'significant' growth for Cobb," Marietta Daily Journal, November 15, https://www. mdjonline.com/sports/atlanta_braves/lee-predicts-unanimous-braves-vote/article_b5e1ba31-fe335cd5-a3c0-b7bb8f2b9d86.html, (accessed May 7, 2021)

Hall JC, Matti J, Zhou Y (2020) The economic impact of city-county consolidations: a synthetic control approach. Public Choice 184(1-2):43-77

Horn BP, Cantor M, Fort R (2015) Proximity and voting for professional sporting stadiums: the pattern of support for the Seahawk stadium referendum. Contemp Econ Policy 33(4):678-688

Hotchkiss JL, Moore RE, Rios-Avila F (2015) Reevaluation of the employment impact of the 1996 Summer Olympic Games. Southern Econ J 81(3):619-632

Hotchkiss JL, Moore RE, Zobay SM (2003) Impact of the 1996 summer olympic games on employment and wages in Georgia. Southern Econ J 69(3):691-704

Humphreys BR (2019) Should the construction of new professional sports facilities be subsidized? J Policy Anal Manag 38:264-270

Humphreys BR, Nowak A (2017) Professional sports facilities, teams and property values: evidence from NBA team departures. Reg Sci Urban Econ 66:39-51

Humphreys BR, Pyun H (2018) Professional sporting events and traffic: evidence from U.S. cities. J Reg Sci 58:869-886

Humphreys BR, Zhou L (2015) Sports facilities, agglomeration, and urban redevelopment. Reg Sci Urban Econ 54:60-73

Islam MQ (2019) Local development effect of sports facilities and sports teams: case studies using synthetic control method. J Sports Econ 20:242-260

Johnson BK, Groothuis PA, Whitehead JC (2001) The value of public goods generated by a major league sports team. J Sports Econ 2(1):6

Johnson BK, Mondello MJ, Whitehead JC (2007) The value of public goods generated by a National Football League team. J Sport Manag 21(2):123-136 
Johnson BK, Whitehead JC, Mason DS, Walker GJ (2012) Willingness to pay for downtown public goods generated by large, sports anchored development projects: the CVM approach. City Cult Soc 3(3):201-208

Johnson C (2021) "The impact of the Olympic Games on employment growth," Manuscript

Klepal D (2013) "Cobb town hall meeting about Braves stadium draws hundreds," Atlanta JournalConstitution, November 21, https://www.ajc.com/news/local-govt--politics/cobb-town-hall-meeti ng-about-braves-stadium-draws-hundreds/bXG2M9eXoYxLW0Zro149KJ/, (accessed June 3, 2020)

Lee T (2016) "County is moving in right direction," Marietta Daily Journal, July 24, https://www.mdjon line.com/opinion/tim-lee-county-is-moving-in-right-direction/article_eeca2522-5157-11e6-a9e707e39a46db44.html, (accessed May 14, 2021)

Locke SL (2019) Estimating the impact of Major League Baseball games on local air pollution. Contemp Econ Policy 37:236-244

Lutz M (2016) "Battlelines drawn over Braves stadium in Cobb chairman race," Atlanta Journal-Constitution, July 6, https://www.ajc.com/news/local-govt--politics/battlelines-drawn-over-braves-stadi um-cobb-chairman-race/Dr4B6SonX6NbafFpHBiV3M/, (accessed May 14, 2021)

Mares D, Emily B (2019) Major League Baseball and crime: opportunity, spatial patterns, and team rivalry at St. Louis Cardinal games. J Sports Econ 20:875-902

Marie O (2016) Police and thieves in the stadium: measuring the (multiple) effects of football matches on crime. J R Stat Soc Series A (Stat Soc) 179:273-292

Matheson V (2019) Is there a case for subsidizing sports stadiums? J Policy Anal Manag 38:271-277

Montolio D, Planells-Struse S (2019) Measuring the negative externalities of a private leisure activity: hooligans and pickpockets around the stadium. J Econ Geogr 19:465-504

Oates WE (1969) The effects of property taxes and local public spending on property values: an empirical study of tax capitalization and the Tiebout hypothesis. J Polit Econ 77(6):957-971

Propheter G (2019) "Estimating the effect of sports facilities on local area commercial rents: evidence from Brooklyn's Barclays Center," J Sports Econ, 91-114

Pyun H (2019) Exploring causal relationship between Major League Baseball games and crime: a synthetic control analysis. Empir Econ 57:365-383

Rees DI, Schnepel KT (2009) College football games and crime. J Sports Econ 10:68-87

Rosentraub MS (2014) Reversing urban decline: Why and how sports, entertainment, and culture turn cities into major league winners. Routledge, England

Tiebout CM (1956) A pure theory of local expenditures. J Polit Econ 64(5):416-424

Tu CC (2005) How does a new sports stadium affect housing values? The case of FedEx Field. Land Econ 81(3):379

Yu Y, Nicholas Mckinney C, Caudill SB, Mixon Jr FG (2016) Athletic contests and individual robberies: an analysis based on hourly crime data. Appl Econ 48:723-730

Publisher's Note Springer Nature remains neutral with regard to jurisdictional claims in published maps and institutional affiliations. 